\title{
Measuring View Preferences in Cities: a Window onto Urban Landscapes
}

\begin{abstract}
Landscape plays a crucial role in modern life for urban dwellers although the majority of their time is spent indoors. In this context, window view is the dominant way of connecting urban dwellers to landscapes. The visual quality of urban environments can have a great influence on the quality of life. But how can visual quality be assessed?

This paper presents a novel method, Active Perception Technique (APT), to measure visual preference for urban scenes. Windowscape is used as a convenient tool using graphic responses to draw from memory what landscape people recall seeing. APT is designed to both identify the most and least visually preferred features of urban windowscapes and to predict preference for windowscapes.
\end{abstract}

Results show that natural features of urban windowscapes were preferred over built ones. However, some natural features contributed more strongly to overall preference than others. Preferences for some features were found to differ across home and workplace windowscapes. Personal association with features was also found to impact on visual preferences.

Results obtained from APT can be useful for policy makers, and planners to enhance the visual quality of built environments. APT may also have other uses; including examining the perceived significance of cultural features in everyday urban landscapes.

KEYWORDS: Urban Landscape, Preference, Windowscape, Active Perception Technique, Green Infrastructure

\section{INTRODUCTION}

The landscape contributes an important part to the quality of life for people everywhere: in urban areas as well as for those living out in the countryside [1]. However, the fact that most people are living in cities means that it is more important to focus on how the urban landscape affects the quality of life there. Urban dwellers spend the majority of their time indoors [2] and contact with the outside world is mostly limited to what they can see through their window. Hence, the quality of life of urban dwellers is associated with the visual quality of their windowscapes. However, this raises the question "how do we measure the visual quality of landscape in an urban context'?

Assessing preferences for natural landscapes is an established field of study. It is, however, not clear if findings from these studies are applicable to urban landscapes [3]. Moreover, there is relatively limited research on urban landscape preferences [4]-[8]. Two reasons account for the lack of research in this area. First, urban areas have highly complex structures, which makes assessing preference determinants difficult. Second, there are significant shortcomings with methods that have been used 
in studies of natural landscape preferences and hence it is necessary to question their applicability for studying urban landscapes.

Most studies into landscape preference have used experiments in a laboratory setting consisting of showing participants photographic images of scenes. Thus the experimental subjects did not have the holistic experience of the landscape, itself [9], [10]. Stamps [11] has identified over 1300 references that used photographs to evaluate landscape preference. Hence, very little is known on how real places are experienced [12]-[14], [10].

The method of asking people to rate photographs of the scenes cannot capture the subjective value of the urban landscape as experienced on a daily basis. In addition, "a photograph is totally unable to convey the life of the scene; [being] unable to discriminate; it merely records everything at one instant" [15, pp. 360-361]. Dearden [16] and Zube, Pitt, and Anderson [17] warn researchers to be cautious in their use of photographs and emphasise that photographs and actual environments are not completely interchangeable. Uzzell [18, p. 9] adds, "[i]t seems highly likely that the preferences expressed on the basis of two-dimensional photographs are different to those which might be made in situ". As Wohlwill [19] has rightly pointed out, a photograph cannot capture the ambience of an urban environment, which is composed of sonic and dynamic components as well as visual.

Although the results concerning validity of using photographs are inconsistent [11], [12], [20], [21]; much research in landscape preference continues to use static images. Research on urban landscapes has shown that urban images containing natural features (vegetation and water) are liked better than those without [22]-[25]. The presence of water features in urban landscapes is also found to have a positive effect on the economic values of properties [26]-[28]. However, open questions remain as to whether such results hold for actual scenes seen on a daily basis, and whether all natural features are equally preferred. Moreover, it is not yet clear how to combine common natural and built features to predict preference for urban landscapes.

This paper addresses the aforementioned limitations and gaps, with the objective of developing a novel method for measuring the visual quality of an urban landscape in a real context. Hence, the main research questions are:

1) How do urban dwellers perceive the visual quality of their everyday landscapes? and,

2) How to measure their urban landscape preferences in a real context?

The significance of this research rests on the fact that preferences reflect how well the given environments support well-being (e.g. [29], [30]). Research on the impact of landscape preferences on wellbeing has shown that an attractive windowscape is more than an amenity and underpinning this preference is a fundamental issue of psychological well-being and physical comfort [31], [32]. For instance, a cross-sectional survey on office workers in the Netherlands showed that attractive window views reduced discomfort (e.g. concentration problems and headache) [33]. A study by Lottrup and his colleagues showed that a view of natural elements was related to high view satisfaction, which then contributes to high work ability and high job satisfaction [34]. An archival study of past residents of a nursing home revealed a significant negative correlation between people view (view to parking lots, the front entrance, or a yard) and length of stay, while view of greenery had no effect on this matter [35].

Being able to identifying environmental characteristics, which can contribute to the enhancement of the visual quality of urban areas, will also be useful to policy makers, architects, urban 
planners, and environmental experts [36]. The results can help architectural and urban designers to provide urban environments, which promote psychological well-being.

\section{ACTIVE PERCEPTION TECHNIQUE: AN OVERVIEW OF THE ORIGINAL METHOD}

The central idea of the theoretical framework stems from research in environmental cognition, which claims that the real world is too complex to be processed completely by inhabitants. Hence, people create their own version of reality by selecting only those environmental features that produce affective responses. In this present work, it is similarly argued that viewing an urban landscape on a daily basis makes some features stand out more than others (depending on environmental and personal factors). Preferences held for these prominent perceptual features are proposed to be the determinants of preference for the overall landscape. The Active Perception Technique (APT) aims to capture these features and to explore the relationship between visual-quality values of these features and the overall view. As opposed to using photographs for environmental sampling, APT uses 'windowscapes viewed on a daily basis' as a convenient, useful tool. The main advantage of using window-views is the possibility to study the urban landscape in its real-context from the point of view of a building occupant.

APT originates from Kevin Lynch's [37] seminal work, 'Image of the City', and Nasar's [38] study, 'The Evaluative Image of the City'. Because he was interested in how people make sense of the vast amount of visual information in a city, Lynch [37] asked research participants to draw a quick sketch of their city as if they were making a rapid description of the city to a stranger. Lynch's analysis predominantly dealt with the effects of physically perceptible objects and the relation between image and physical form. He [37, p. 6] proposed the concept of environmental image, a generalized mental picture of the exterior physical world:

Environmental images are the result of a two-way process between the observer and his environment. The environment suggests the distinctions and relations, and the observer...selects, organizes, and endows with meaning what he sees. The image so developed now limits and emphasizes what is seen, while the image itself is being tested against the filtered perceptual input in a constant interacting process. Thus, the image of a given reality may vary significantly between different observers.

Nasar [38, p. 42] argued "evaluation is central to our perception of and reaction to the environment" and Lynch's theory of the city image can be strengthened by measuring the emotional meaning that an individual brings to the image. Nasar asked residents of two cities to identify areas that they liked visually and areas they disliked, and to describe the physical features accounting for their evaluation.

Nasar's concept of likability was used to develop the APT. The term likability refers to "the probability that an environment will evoke a strong and favourable evaluative response among the groups or the public experiencing it" [39, p. 3]. Likability derived from what Gibson has labelled affordance - the reciprocal relation between environmental properties of things and the active perceiver [40]. For instance, a road affords (supports) walking or driving. According to Nasar (1990), likability has two components imageability and affect. In other words, "for a favourable image, features 
must stand out as both memorable and likable" [39, pp. 60-61]. APT, accordingly, is composed of two parts:

- Capturing the imageable features of urban windowscape,

- Determining preferences for those features and their influence on overall windowscape preference.

Research participants were asked to sketch from memory what they could recall of the view from their window. It was stressed to the participants that their sketching technique was not important. They were asked to number each feature of the view in the order in which they had been drawn, to express their preferences towards them using the five-point Likert scale by annotating each with a letter: (A) for Strongly like, (B) for Like, (C) Not Sure, (D) for Dislike, and (E) for Strongly Dislike and to label these features. At the end, they were asked to rate their feelings towards the view in general using the same Likert scale. Participants were also instructed to 'label and number' each feature as they drew their sketches. Labelling the features ensure that differences in drawing ability do not

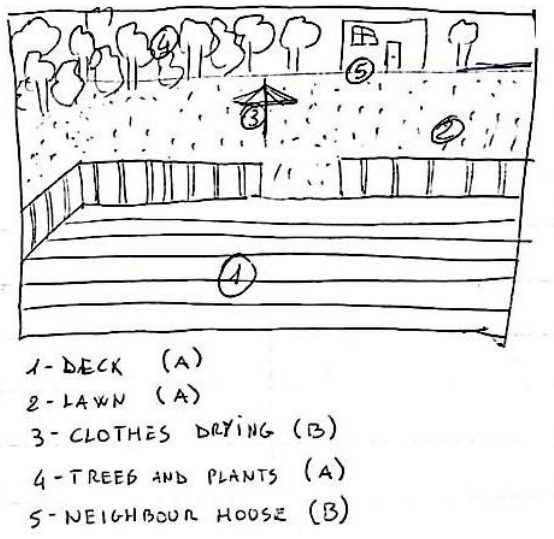

Figure 1 An example of data collected confound sketch output and consequently the result of the study. Figure 1 shows an example of data collected. This view was rated as Strongly Liked. These sketches were then compared against photos taken from the same viewpoint in order to compare the actual with the perceived view. At the end, participants were also asked to state some demographical information such as their age, gender, ethnicity and urban background.

\subsection{Participants}

The method is demonstrated by studying postgraduate students of two Auckland universities. A target population was identified as postgraduate research students, who had been assigned university workplaces in rooms with outdoor views. There is an advantage to using students as they have no vested interest in the workspace as employees might have (their response may impact on their job), and therefore the answers tend to be more objective. It was decided to use postgraduate students because they are the only students who are usually assigned workplaces at universities and spend most of their times within their workplaces.

Due to the qualitative nature of the study, participants were not expected to constitute a representative sample. However, individuals with different ethnicity and educational backgrounds and genders were recruited. As the research progressed, additional participants were recruited by purposeful sampling in order to achieve desired diversity of urban backgrounds. 158 postgraduate research students were interviewed. The gender distribution of the survey was well balanced with $51 \%$ female and 49\% male. Most of the participants were in the age group of 26-35 (93 students, 59\%); followed by the group $<26$ (48 students, $30 \%$ ) and $11 \%$ were above the age 35 . The study participants were ethnically diverse (32\% Far East, $43 \%$ of European origin, $13 \%$ Middle East, $12 \%$ other). In terms of urban background, participants are fairly well distributed, with $53 \%$ lived most of their childhood in standalone houses within village, suburbs and towns and the rest lived in apartments within cities or mega-cities and had no access to private gardens. 
Participation in the study was not limited to a particular university building or campus. However, $86 \%$ of the participants were based on the University of Auckland city campus, while the rest distributed among six different campuses around the city. Participants were mostly from the faculties of Science (24\%), National Institute of Creative Arts and Industries (NICAI) (22\%), Engineering (16\%) and Bioengineering Institute (12\%). The low response from postgraduate students in the University of Auckland Business School is due to the school policy that the research advertisement could only be distributed through the School Facebook page. The view of the participants from their offices were diverse depending on the location of the buildings in the campus and their rooms/desks within that buildings.

\section{$2.2 \quad$ Procedure}

Face-to-face questionnaire-based interview sessions were used as a tool for data collection. The participants were self-selected volunteers following advertisement of the aims and objectives of the project. Recruitment was achieved by invitation via fliers, emails, Facebook, and universities' newsletters, or group presentation in the postgraduate student meetings. All those who responded to advertisements or submitted their email addresses were contacted to schedule a date and time for an interview.

Participants were presented with a regular lead pencil, eraser, and a set of coloured pens for the sketching aspect of the survey. No rules or guidance on how to draw mental images were given to the participants. The only restriction was that the image should not be copied from the outdoor view but drawn from memory. Participants were also supervised to ensure that they would not look out of their office window while drawing. If a lack of confidence with drawing skills were observed by the researcher or expressed by participants themselves, writing down the name of features instead of drawing them was allowed. However, only one participant chose to write some of the features names under her sketch without drawing them.

For the office-view sketches, participants were advised to draw the view they could see when they were sitting behind their desks. For the house views the choice of view was more complicated since the variety of participants' living situations meant that several had access to more than one window in their homes. In these cases, participants were advised to choose between their bedroom and living room view, to represent the one in which they spend most of their time. Participants were encouraged to talk freely during sketching. The interview typically took 20 to 30 minutes to complete. Photos were taken of their office window views by the first author, and the participants were requested to email the photos of home views.

Photographs still play a role as a research instrument in this study; however, the approach to the use of photographs is different from photo protocol studies, which sees photos as a reasonable surrogate of the physical environment. In this research, a photograph is considered as an objective, definite of the view outside the window. Photographs capture exactly what is there to be seen and are compared against sketches to gain insight into the differences between the objectiveness of the environment and the subjective way of seeing the windowscape (or reconstructed image of the view).

The majority of interviews were conducted between July and August; only $19 \%$ were held between November and December. Initially, it was intended to repeat the study in the opposite season. As the data collection started and progressed in wintertime, it was noticed that trees and greenery were drawn as if they still had leaves and/or flowers present. Absence of seasonal variation might be 
because sketches were drawn from memories. Based on this observation, it was decided to cancel the follow-up interview sessions.

\subsection{Analysis}

Following the data collection, all sketches were scanned, and a digital library built by placing sketches and the corresponding photographs next to each other on one page using Adobe Photoshop CS6. To avoid identification, all respondents are referred to by code numbers. The montage collection of sketches and photographs together with participants' socio-demographic datasheet were then uploaded into NVivo 10 for content analysis. NVivo is a qualitative data analysis software program designed "to manage, access and analyse qualitative data and to keep a perspective on all of the data, without losing its richness" [41].

Content analysis is an empirically grounded method, which has been widely used in the studies involving with visual data [42], [43]. The purpose of using content analysis was to identify the most common features within the views (e.g. trees, street, buildings). Frequency data generated by content analysis was analysed using SPSS. Statistical comparison was done by non-parametric methods (Mann Whitney U-test). For the statistical data analysis, responses were recorded as $A=5, B=4, C$ $=3, D=2$, and $E=1$. A p-value less than 0.05 was considered significant for all tests.

\section{RESULTS AND DISCUSSION}

The dataset comprises 158 respondents, 153 office-view sketches and 157 home-view ones, and 304 corresponding photos of the views. Missing data is because either a few participants did not have access to windows from their workplaces $(n=5)$ or their places of residence $(n=1)$, or

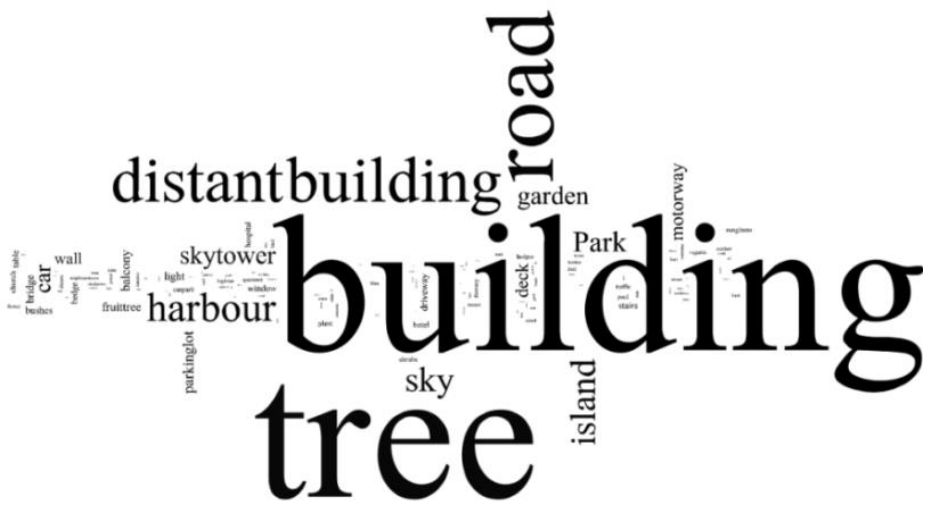

Figure 2 Word cloud made of words from features drawn/labeled in the sketches they did not email their home-view photographs $(n=6)$. On average four features were drawn in each sketch, and the results presented here are obtained from the analysis of more than 1240 drawn features.

The collected data covers a variety of Auckland windowscapes. The majority of window views provided visual access to some form of greenery (88\%). 57 participants could see parklands from their windows; while $13 \%$ of the home and office views were completely blocked by building(s) located immediately outside the windows $(n=39)$. Roading such as motorways, streets, roads, and driveways was visible from 103 of the window views and parking lots were identified in 25 sketches.

In order to find the most common windowscape features, all drawn and labelled features were compiled in an Excel spreadsheet and imported into NVivo. NVivo was set to group similar features together: e.g. road(s) or street(s) were merged into the word road. The results of this analysis using a word cloud of the phrases in which font size is associated with relative frequency are shown in Figure 2Error! Reference source not found. Since the research was conducted in an urban area, it is not surprising that (distant) building appeared as the most frequently drawn and/or labelled features of the views. This was followed by tree, road, harbour, the sky, and island respectively. 
A summary of the preferences for each windowscape feature is presented in Error! Reference

source not found.. The percentage is calculated by counting how each feature is rated on the Likert scale (e.g. 'Strongly Like') and dividing them by the total numbers the feature appeared in the sketches. In this figure, the term 'Blocking Building' describes a building located immediately outside a window, which interrupted the lines of sight.

A straightforward result of this analysis revealed that urban natural features were preferred over urban built ones. Large bodies of water and the sky were the most preferred features within urban windowscapes. Similar results were reported by Howley and O'Donoghue [44] who asked their survey respondents to rate a list of 14 landscape elements based on how much they like each of these on a 5-point Likert scale. The researchers found that water bodies were the most liked landscape attribute, followed by hills/mountains.

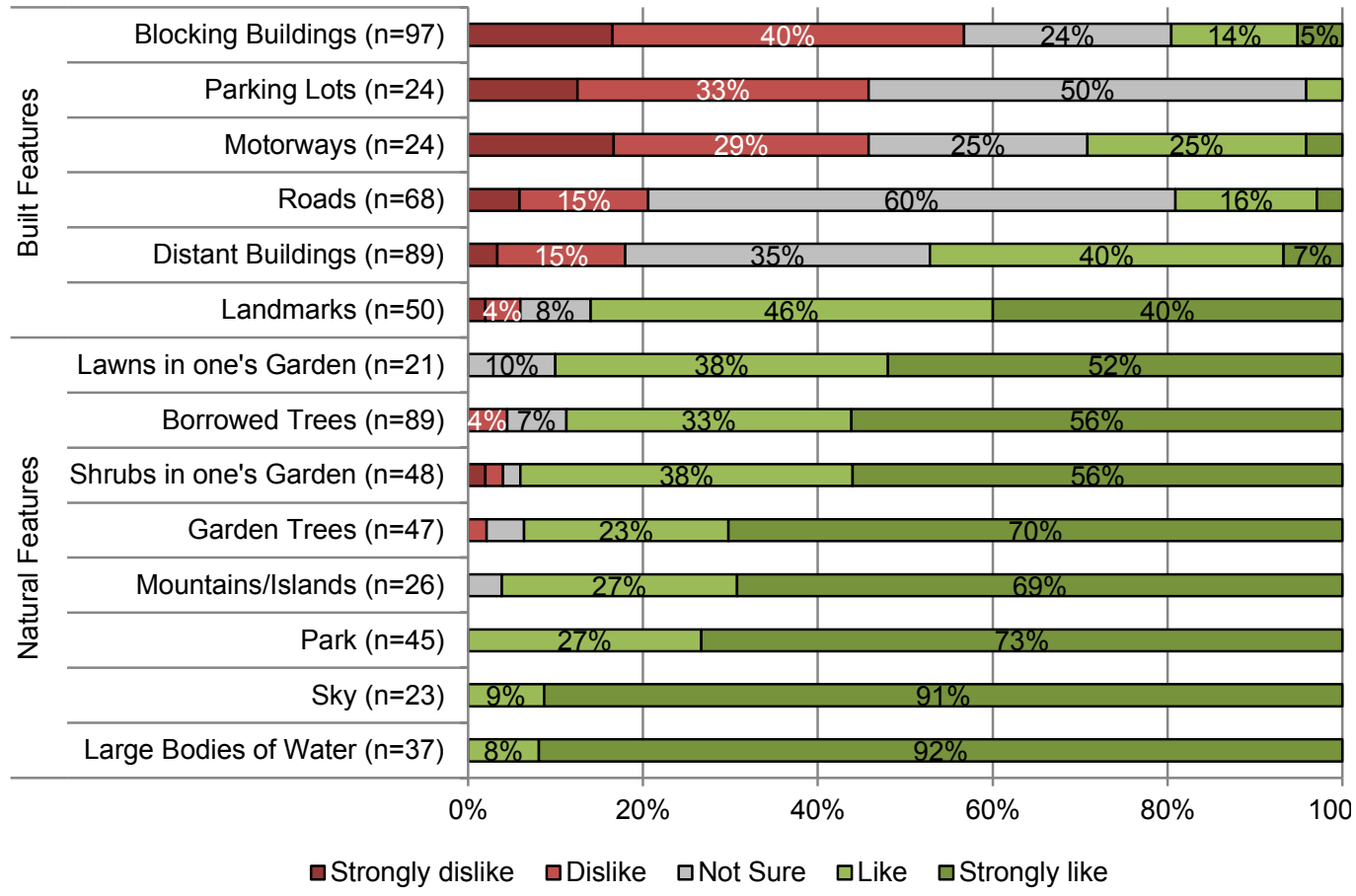

Figure 3 Feelings attached to the most common features of the view

Sky is the most under-researched feature in landscape studies as researchers using photoprotocol usually asked their respondents to rate the scenes without reference to the appearance of the sky (e.g. [45]). This is because the presence of sky in landscape photographs is more related to photocomposition and measuring its significance to landscape preference may not provide useful information using this method. However, APT reveals that the sky is considered as one of the most attractive features of urban landscapes. Preference to see the sky has been previously reported in a few windowscape studies (e.g. [46], [47]) and was linked to the preference to see the weather out of the window [47].

'Park land' was the most-preferred type of greenery rated by $73 \%$ as strongly like, followed by garden trees (rated strongly liked by $70 \%$ ). The respondent's own lawns were the least preferred feature in urban natural category. This finding was in line with the results of a study on workplace window-views which found that flowers, trees, and park-like environment increased the odds of being 
satisfied with the views, however, no significant relationship was found between view satisfaction and presence of 'mowed lawns' [48]. The difference in preferences of tree and grass might be because the visual effect of trees is three-dimensional [49], and that they are relatively uncontrolled in their form (no straight edges). Instrumental functions of urban trees, shade and shelter, can also explain the reasons why trees are valued more than lawns (Gibson's [40] affordances).

One of the interesting and novel results obtained from the APT application was finding that personal association had an impact on preferences for greenery. For instance, the percentage of the respondent's garden trees rated as 'strongly like' was higher than borrowed (street or neighbour's) trees. Moreover, comparing photographs with sketches, all twenty-six participants, who could also see greenery outside of their garden, omitted it from their sketches (see Figure 4 for example). Street trees were positively rated on the Likert scale; however, median preference score for views with street trees $(\mathrm{Mdn}=4)$ and without trees $(\mathrm{Mdn}=4)$ were not statistically different, U-test=11537.5, $\mathrm{z}=-.45, n s$. This result suggests that although street trees are visually valued, they are not as powerful as photoprotocol studies suggest in affecting preference visual quality of the urban landscape.
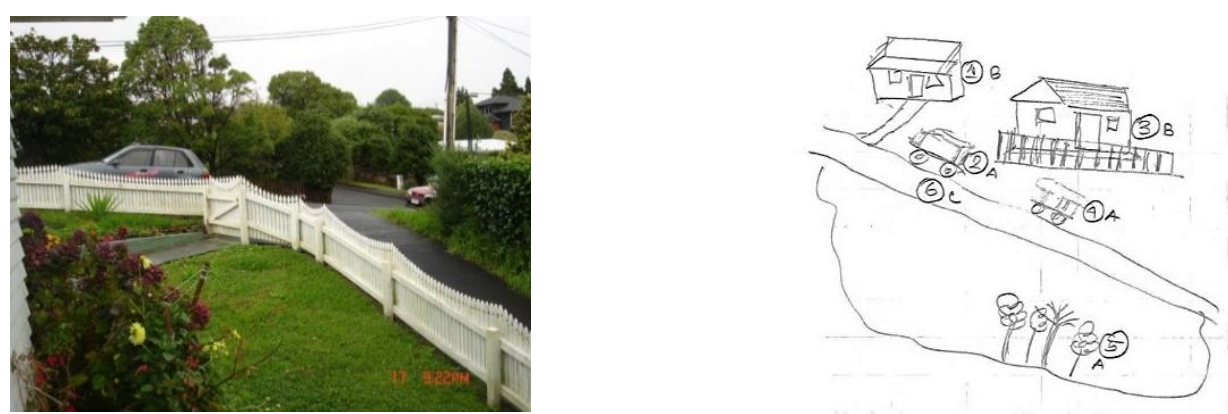

Figure 4 Omission of greenery that was located outside one's garden

Landmarks comprise those features in the sketches that were labelled and rated separately from other 'distant buildings' (buildings that were located in the far distance of the views) indicating that, in the eyes of the observer, they stood out from other buildings. These features are namely Auckland War Museum, Sky Tower, Harbour Bridge, Auckland City Hospital. Landmarks were the most preferred built features, rated as 'strongly like' or 'like' by $86 \%$ of participants. Landmarks were drawn with clear exaggerations (Figure 5) even when their silhouette was only visible on the horizon, suggesting their significance as an urban feature. Herzog, Kaplan, and Kaplan's [50] study on familiar urban places revealed that pictures depicting cultural buildings (e.g. churches, an art museum) were relatively high in preference.
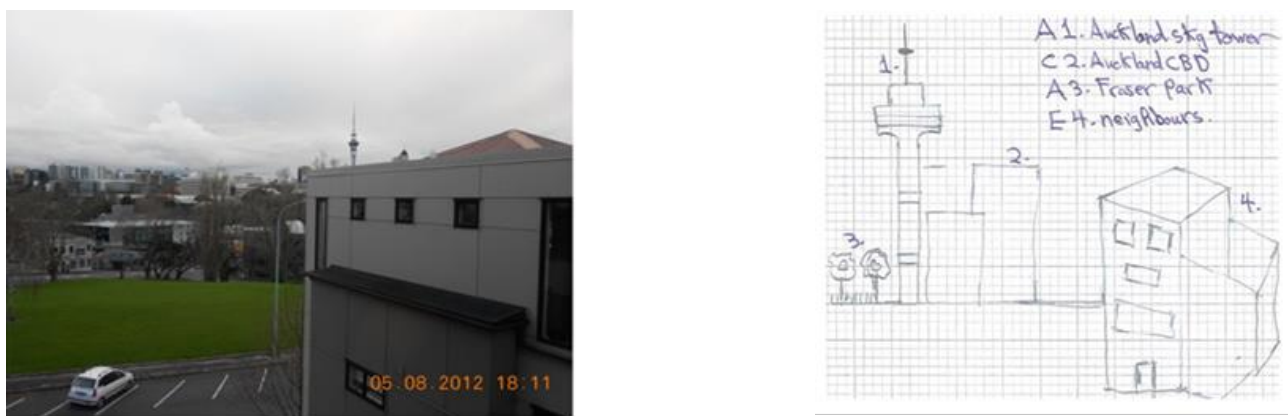

Figure 5 The exaggeration of sky tower in comparison to the photo from the view window.

Parking lots and motorways created negative preferences in $46 \%$ of observers. The majority $(60 \%)$ were indifferent to the presence of roads within their views. However, it was found that the 
percentage of roads negatively scored on the Likert scale was larger and significantly different in home views $(33 \%)$ than in office views $(9 \%), U$-test=390.5, $z=-2.615, p<0.01, r=-.22$. Such a result is not surprizing as the research conducted in real setting and aural components of the urban landscape can have an impact on visual preferences. In particular, we believe that a higher need for acoustic privacy in residential places did not let the participants of our study judge the roading based purely on visual contribution.

Blocking buildings (that were located in the immediate foreground of the views) were the least preferred feature with $56 \%$ rating them as disliked or strongly disliked. Similarly, a study on view preferences on human-made islands reported that the presence of residential buildings at a close distance were the most important determinants of a negative assessment of the view [51]. Herzog found that blocked urban scenes were rated lower in preference than photos depicting well-structured scenes with an intermediate level of openness [52].

\subsection{The Effect of Features on Windowscapes Preferences}

This section investigates whether the presence of each feature within a view has any influence on the overall preferences for the view. The window views are categorised into four preference categories (strongly liked views, liked views, indifferent to the views and strongly disliked \& disliked views) depending on how the overall view have been rated by the participants. As only four windowscapes were rated as Strongly Disliked; it was decided to merge them into the Disliked category.

An analysis of the frequency of the appearance of features in each preference category was carried out with the aim of determining if a combination of common urban features can be found for making predictions about windowscape preferences. For this analysis, all the features that appeared in windowscapes rated as 'strongly like', for instance, were listed in a spreadsheet, and uploaded into NVivo. The result of this analysis is presented in Table 1. The percentage is calculated by dividing the number of times each feature appeared in a view preference category by the total number of features within that category.

Looking at Table 1, it is clear there are more features within the word clouds of 'strongly like' window-views compared to the ones in 'strongly dislike' \& 'dislike' categories. This difference is because complexity, the average number of features in the view, has an influential factor on view preferences [46], [53]. As the research mainly involved an urban situation, the presence of buildings within the views was inevitable. Accordingly, it is not surprising that blocking and distant buildings appeared in all types of windowscape with different preference scores. The percentage of the times Blocking Building(s) appeared in strongly disliked and disliked views is significantly higher than the times this feature is drawn in the preferred views. In contrast, the number of times distant buildings are noted in the participants' sketches increases with increased preference for the views. This increase reaches the point where buildings in the far distance were more frequently mentioned in the strongly liked category than buildings in the foreground. This finding should not be taken to mean that the appearance of distant buildings positively affects preferences for windowscapes. Since this research was conducted in an urban area, the presence of distant buildings merely indicates that these windowscapes were offering long views. The presence of road networks (driveway, road/street, motorway) in the views also seems to be a determining factor in windowscape preferences. As can be seen, there is a correlation between the percentage of the time natural features are mentioned in the 
views and preferences for the view. However, each natural feature seems to have a different power in affecting the windowscape preferences. For instance, own garden trees or the Park land have only appeared in the word clouds of liked and strongly liked categories, suggesting that their appearance is likely to be associated with positive preferences of the views. Borrowed trees, however, appeared in all the word clouds, which do not seem to be associated with windowscape preference. This finding supports the result (see Figure 3) suggesting that borrowed trees are one of the least preferred features of urban greenery.

Table 1 Frequency of each features appeared in each window views preference category

\begin{tabular}{|l|l|l|l|l|l|l|l|l|}
\hline \multirow{2}{*}{ Rank } & \multicolumn{2}{l|}{$\begin{array}{l}\text { Strongly Disliked \& } \\
\text { Disliked Views ( } \mathrm{n}=77)\end{array}$} & \multicolumn{2}{l|}{$\begin{array}{l}\text { Indifferent to the Views } \\
(\mathrm{n}=82)\end{array}$} & \multicolumn{2}{l|}{ Liked Views (n=269) } \\
\cline { 2 - 10 } & Features & $\%$ & Features & $\%$ & Features & $\%$ & \multicolumn{2}{l}{ Strongly liked Views (n=220) } \\
\hline 1 & Blocking Building & $43 \%$ & Blocking Building & $32 \%$ & Distant Building & $22 \%$ & Distant Building & $26 \%$ \\
\hline 2 & Road Networks & $22 \%$ & Borrowed Trees & $18 \%$ & Road Networks & $16 \%$ & Own (Garden) Trees & $12 \%$ \\
\hline 3 & Borrowed Trees & $19 \%$ & Distant Building & $18 \%$ & Blocking Building & $14 \%$ & Borrowed Trees & $11 \%$ \\
\hline 4 & Distant Buildings & $10 \%$ & Road Networks & $17 \%$ & Borrowed Trees & $13 \%$ & Harbour & $10 \%$ \\
\hline 5 & Parking Lot & $5 \%$ & Parking Lots & $7 \%$ & University Owned Tree & $11 \%$ & Domain Park & $10 \%$ \\
\hline 6 & & & Sky & $7 \%$ & Domain Park & $9 \%$ & Road Networks & $9 \%$ \\
\hline 7 & & & & & Own (Garden) Trees & $7 \%$ & Sky & $8 \%$ \\
\hline 8 & & & & & Parking Lots & $5 \%$ & University Owned Trees & $8 \%$ \\
\hline 9 & & & & Lawns & $3 \%$ & Lawns & $5 \%$ \\
\hline
\end{tabular}

\section{CONCLUSIONS}

This study uses a novel method for measuring urban landscape preferences from the point of view of daily observers. Active Perception Technique (APT) consists of collecting information from a brief sketch, a questionnaire, and a windowscape photograph. APT allowed participants to engage actively with their views by drawing what they could recall seeing out of their windows. Photographs still play a role as a research instrument in this study, though the use differs from photograph study protocols. Traditional protocols see photographs as a reasonable surrogate of the physical environment. In this research, photographs are considered to be tools, as an objective record of the view outside. Photographs capture exactly what is there to be seen, and a comparison between photographs and sketches indicates how a person perceives the view, which can contrast greatly with the reality documented in the photograph.

Participants in this study had visual contact with a view on a daily basis; therefore, the results reveal the reaction of participants to a three-dimensional, ever-changing environment. Results obtained from APT have a clear potential to be useful for policy makers, and planners to enhance visual quality of built environments and to provide more likable and liveable cities. It may also have an economic impact on the value of buildings. This has already been demonstrated for water views [27], [28]; so why not for preferred landscapes. It can also help to identify particularly influential features of urban landscape preference, and hence aid in the development of guidelines for improving the visual quality of cities. For instance, in this study it was found that trees that were owned by observers evoked a stronger positive effect than street trees. Therefore, it may be a better choice to leave maintenance of street trees in residential areas to the local community who are willing to undertake such responsibility. In this case, the local council should inspect the street trees occasionally to ensure that the trees are well maintained. 
Since APT was tested using only postgraduate students, we have no proof of the generalizability of our results. However, one of the principal objectives of this work was to show the applicability of the technique; the representativeness of the research sample was not a priority. Although tertiary students (mainly undergraduate students) have been widely used as participants in surveys of landscape preferences studies (see [54] and [55] for detail reviews); researchers did not reach a consensus if students can satisfactorily substitute for the general public (cf. [56] and [57]). Participants of the present research were overwhelmingly young $(<35,89 \%)$ and highly educated (73\% Ph.D. students). The generalizability of conclusions drawn from results of the study may well be somewhat limited by differences in level of education, age group and the relatively small number of individuals interviewed. Note especially that there is some evidence that age [21] and level of education (e.g. [58]) seem to affect landscape preferences.

The external validity (generalizability) of the study findings is also limited by 1 ) the findings only represented the landscape preferences of those postgraduates who had access to window views in their office and/or home; 2 ) the possibility that those postgraduate students who were more satisfied with their views might have volunteered to participate in the study. The current work would benefit by being repeated in different population groups.

Although this study demonstrated the method in the urban landscape, APT has a great potential to be used as a decision tool in cultural landscape management. For instance, as cities intensify one of the challenges in management of urban cultural landscapes is what to conserve. APT can help to identify significant cultural features in an urban environment; also, can justify preserving existing view shafts to these features as the city intensifies. APT can also be used to understand whether urban landscape quality have any influence on health and well-being of the observers. This can be done for instance by asking the observers to rate their perceived health or expose whether they have been diagnosed with any health issues in the last year or so.

Research has shown that in addition to physical characteristics of the landscape, observers' demographic characteristics can have an influence on windowscape preferences. Current research has found similar results revealing that the urban background and gender can have influence on preferences of urban landscape; in particular blocked views. However, these results will be presented in the future publications.

In this research, a homogeneous group (postgraduate students) were chosen to demonstrate the method. However, APT could be used to show differences in landscape preferences between differing groups, sub-cultures, and special populations. For instance, APT can compare preferences of tourists and local residents, which can guide urban planners and policy makers when allocating land to residential and touristic uses. APT could be a tool for evaluating the difference between social and cultural landscapes and showing strengths and weaknesses of the visual quality of each. Such information can be used to improve the appearance of urban areas and make a more pleasant place to live.

Although preference may compass other visual dimensions of urban cultural landscapes such as tranquillity and security, APT can be modified to measure these aspects too. For instance, APT can provide useful information about tranquillity values of visual contact with some cultural heritage such as mosques or churches. 


\section{REFERENCES}

[1] M. Déjeant-Pons, "The European Landscape Convention," Landsc. Res., vol. 31, no. 4, pp. 363-384, 2006.

[2] C. A. Shoemaker, Ed., Interaction by Design: Bringing People and Plants Together for Heatlh and Well-Being, 1st ed. Wiley-Blackwell, 2002.

[3] R. Home, N. Bauer, and M. Hunziker, "Cultural and Biological Determinants in the Evaluation of Urban Green Spaces," Environ. Behav., vol. 42, no. 4, pp. 494-523, Jul. 2010.

[4] M. P. Galindo and M. C. Hidalgo, "Aesthetic preferences and the attribution of meaning: Environmental categorization processes in the evaluation of urban scenes," Int. J. Psychol., vol. 40, no. 1, pp. 19-27, 2005.

[5] M. C. Hidalgo, R. Berto, M. P. Galindo, A. Getrevi, M. Ambiente, and C. Humano, "Identifying attractive and unattractive urban places: categories, restorativeness and aesthetic attributes," Medio Ambiente Comport. Hum., vol. 7, no. 2, pp. 115-133, 2006.

2012.

[6] I. C. Kaymaz, "Chapter 12: Landscape Perception," in Landscape Planning, InTech,

[7] R. Crane and R. Weber, The Oxford Handbook of Urban Planning. Oxford University

Press, 2012.

[8] H. Hellinga, "Daylight and View: The influence of windows on the visual quality of indoor spaces," PhD thesis, Delft University of Technology, 2013.

[9] M. V. Giuliani and M. Scopelliti, "Empirical research in environmental psychology: Past, present, and future," J. Environ. Psychol., vol. 29, no. 3, pp. 375-386, Sep. 2009.

[10] C. W. Thompson, "Landscape perception and environmental psychology," in The Routledge Companion to Landscape Studies, Routledge, 2013.

[11] A. E. Stamps, "Use of Photographs to Simulate Environments: A Meta-Analysis," Percept. Mot. Skills, vol. 71, no. 3, pp. 907-913, Dec. 1990.

[12] R. B. Hull IV and W. Stewart, "Validity of photo-based scenic beauty judgments," J. Environ. Psychol., vol. 12, no. 2, pp. 101-114, Jun. 1992.

[13] P. H. Gobster, "An Ecological Aesthetic for Forest Landscape Management," Landsc. J., vol. 18, no. 1, pp. 54-64, Mar. 1999.

[14] M. S. Myers and C. W. Thompson, "Chapter 3: Interviews and Questionnaires," in Crossplan: Integrated, participatory landscape planning as a tool for rural development, Simon Bell, Ed. Edinburgh: Forestry Commission, 2003, pp. 17-29.

[15] D. C. D. Pocock, "Valued Landscape in Memory: The View from Prebends' Bridge," Trans. Inst. Br. Geogr., vol. 7, no. 3, pp. 354-364, Jan. 1982.

[16] P. Dearden, "Landscape Assessment: The Last Decade," Can. Geogr. Géographe Can., vol. 24, no. 3, pp. 316-325, 1980.

[17] E. H. Zube, D. G. Pitt, and T. W. Anderson, "Perception and prediction of scenic resource values of the Northeast.," 1975.

[18] D. L. Uzzell, "Environmental psychological perspectives on landscape," Landsc. Res., vol. 16 , no. 1, pp. 3-10, Mar. 1991.

[19] J. F. Wohlwill, "Environmental aesthetics: the environment as source of affect," in Human Behavior and Environment, New York: Plenum, 1976, pp. 37-86.

[20] T. C. Daniel and M. M. Meitner, "Presentational Validity of Landscape Visualizations: The Effects of Graphical Realism on Precieved Senic Beauty of Forest Vistas," J. Environ. Psychol., vol. 21, no. 1, pp. 61-72, Mar. 2001.

[21] E. H. Zube and D. G. Pitt, "Cross-cultural perceptions of scenic and heritage landscapes," Landsc. Plan., vol. 8, no. 1, pp. 69-87, Feb. 1981.

[22] T. R. Herzog, "A cognitive analysis of preference for urban nature," J. Environ. Psychol., vol. 9, no. 1, pp. 27-43, 1989.

[23] V. L. Sheets and C. D. Manzer, "Affect, Cognition, and Urban Vegetation Some Effects of Adding Trees Along City Streets," Environ. Behav., vol. 23, no. 3, pp. 285-304, May 1991.

[24] M. White, A. Smith, K. Humphryes, S. Pahl, D. Snelling, and M. Depledge, "Blue space: The importance of water for preference, affect, and restorativeness ratings of natural and built scenes," J. Environ. Psychol., 2010.

[25] E. V. White and B. Gatersleben, "Greenery on residential buildings: Does it affect preferences and perceptions of beauty?," J. Environ. Psychol., vol. 31, no. 1, pp. 89-98, Mar. 2011.

[26] J. J. Kim and J. Wineman, "Are windows and views really better? A quantitative analysis of the economic and psychological value of views," Rep. Univ. Mich., 2005.

[27] O. E. Samarasinghe and B. M. H. Sharp, "The value of a view: A spatial hedonic analysis," N. Z. Econ. Pap., vol. 42, no. 1, pp. 59-78, 2008.

[28] C. Y. Jim and W. Y. Chen, "Value of scenic views: Hedonic assessment of private housing in Hong Kong," Landsc. Urban Plan., vol. 91, no. 4, pp. 226-234, Jul. 2009. 
[29] T. Hartig and H. Staats, "The need for psychological restoration as a determinant of environmental preferences," J. Environ. Psychol., vol. 26, no. 3, pp. 215-226, Sep. 2006.

[30] A. E. van den Berg, S. L. Koole, and N. Y. van der Wulp, "Environmental preference and restoration: (How) are they related?," J. Environ. Psychol., vol. 23, no. 2, pp. 135-146, Jun. 2003.

[31] Leather, P., Pyrgas, M., Beale, D., \& Lawrence, C. (1998). Windows in the Workplace: Sunlight, View and Occupational Stress. Environment and Behavior, 30(6), 739-762.

[32] Tuaycharoen, N., \& Tregenza, P. R. (2007). View and discomfort glare from windows. Lighting Research and Technology, 39(2), 185-200.

[33] Aries, M. B. C., Veitch, J. A., \& Newsham, G. R. (2010). Windows, view, and office characteristics predict physical and psychological discomfort. Journal of Environmental Psychology, 30(4), 533-541.

[34] Lottrup, L., Stigsdotter, U. K., Meilby, H., \& Claudi, A. G. (2013). The Workplace Window View: A Determinant of Office Workers' Work Ability and Job Satisfaction. Landscape Research, $0(0), 1-19$.

[35] O'Connor, B. P., Davidson, H., \& Gifford, R. (1991). Window View, Social Exposure and Nursing Home Adaptation. Canadian Journal on Aging/La Revue Canadienne Du Vieillissement, 10(03), 216-223.

[36] L. E. Jackson, "The relationship of urban design to human health and condition," Landsc. Urban Plan., vol. 64, no. 4, pp. 191-200, Aug. 2003.

[37] K. Lynch, The Image of the City. Cambridge [Mass.]: Technology Press, 1960.

[38] J. L. Nasar, "The Evaluative Image of the City," J. Am. Plann. Assoc., vol. 56, no. 1, pp. 41-53, Mar. 1990. 1998.

[39] J. L. Nasar, The evaluative image of the city. Sage Publications Thousand Oaks, CA,

[40] J. J. Gibson, The Ecological Approach to Visual Perception. Routledge, 1986.

[41] Bazeley, P., \& Richards, L. (2000). The Nvivo Qualitative Project Book. SAGE.

[42] P. Bell, "Content Analysis of Visual Images," in Handbook of visual analysis, London; Thousand Oaks [Calif.]: SAGE, 2001, pp. 10-35.

[43] R. Maggi and C. Scholz, "Finding the Invisible-Quantifying the 'urban beauty'of Dubai via content analysis of photographs," in Instant Cities: Emergent Trends in Architecture and Urbanism in the Arab World., UAE, 2008.

[44] P. Howley and C. O'Donoghue, "Landscape preferences and residential mobility: Factors influencing individuals' perceptions of the importance of the landscape in choosing where to live," J. Landsc. Stud., vol. 4, no. 1, 2011.

[45] R. G. Ribe, E. T. Armstrong, and P. H. Gobster, "Scenic Vistas and the Changing Policy Landscape: Visualizing and Testing the Role of Visual Resources in Ecosystem Management," Landsc. J., vol. 21, no. 1, pp. 42-66, Jan. 2002.

[46] T. A. Markus, "The function of windows-A reappraisal," Build. Sci., vol. 2, no. 2, pp. 97-121, Jun. 1967.

[47] H. Hellinga and G. de Bruin-Hordijk, "Preferences of office workers regarding the lighting and view out of their office," in SOLG Symposium Light, Performance and Quality of Life, 2008, pp. 26-29.

[48] L. Lottrup, U. K. Stigsdotter, H. Meilby, and A. G. Claudi, "The Workplace Window View: A Determinant of Office Workers' Work Ability and Job Satisfaction," Landsc. Res., vol. 0, no. 0, pp. 1-19, 2013

[49] Y. Aoki, Y. Yasuoka, and M. Naito, "Assessing the impression of street-side greenery," Landsc. Res., vol. 10, no. 1, pp. 9-13, 1985.

[50] T. R. Herzog, S. Kaplan, and R. Kaplan, "The Prediction of Preference for Familiar Urban Places," Environ. Behav., vol. 8, no. 4, pp. 627-645, Dec. 1976.

[51] I. Z. Kfir, J. Munemoto, O. Sacko, and Y. Kawasaki, "Evaluation of the view from the dwelling units on man made islands in Osaka bay. Multiple regression analysis based on residents' evaluation and image processing of photographs taken from the living room.," J. Archit. Plan. Environ. Eng., no. 554, pp. 357-364, 2002.

[52] T. R. Herzog, "A cognitive analysis of preference for urban spaces," J. Environ. Psychol., vol. 12, no. 3, pp. 237-248, 1992. 1975.

[53] B. L. Collins, "Windows and people: A literature survey," NBS Build. Sci. Ser., vol. 70,

[54] Lothian, A. (2000). Landscape Quality Assessment of South Australia (PhD Thesis), University of Adelaide.

[55] Stamps, A. E. (1999). Demographic Effects in Environmental Aesthetics: A MetaAnalysis. Journal of Planning Literature, 14(2), 155-175.

[56] Tveit, M. S. (2009). Indicators of visual scale as predictors of landscape preference; a comparison between groups. Journal of Environmental Management, 90(9), 2882-2888. 
[57] Yao, Y., Zhu, X., Xu, Y., Yang, H., Wu, X., Li, Y., \& Zhang, Y. (2012). Assessing the visual quality of green landscaping in rural residential areas: the case of Changzhou, China. Environmental Monitoring and Assessment, 184(2), 951-967.

[58] Vecchiato, D. (2012, February). Valuing landscape preferences with perceptive and monetary approaches: two case studies in Italy (Thesis). University of York. 


\title{
Measuring View Preferences in Cities: a Window onto Urban Landscapes
}

\author{
Leila Mirza ${ }^{1}$, Hugh Byrd ${ }^{2}$ \\ ${ }^{1}$ Auckland City Council, NZ. \\ 2 School of Architecture, University of Lincoln, UK. \\ 11leila.mirza@hotmail.co.nz
}

\section{ABSTRACT}

Landscape plays a crucial role in modern life for urban dwellers although the majority of their time is spent indoors. In this context, window view is the dominant way of connecting urban dwellers to landscapes. The visual quality of urban environments can have a great influence on the quality of life. But how can visual quality be assessed?

This paper presents a novel method, Active Perception Technique (APT), to measure visual preference for urban scenes. Windowscape is used as a convenient tool using graphic responses to draw from memory what landscape people recall seeing. APT is designed to both identify the most and least visually preferred features of urban windowscapes and to predict preference for windowscapes.

Results show that natural features of urban windowscapes were preferred over built ones. However, some natural features contributed more strongly to overall preference than others. Preferences for some features were found to differ across home and workplace windowscapes. Personal association with features was also found to impact on visual preferences.

Results obtained from APT can be useful for policy makers, and planners to enhance the visual quality of built environments. APT may also have other uses; including examining the perceived significance of cultural features in everyday urban landscapes.

KEYWORDS: Urban Landscape, Preference, Windowscape, Active Perception Technique, Green Infrastructure

\section{INTRODUCTION}

The landscape contributes an important part to the quality of life for people everywhere: in urban areas as well as for those living out in the countryside [1]. However, the fact that most people are living in cities means that it is more important to focus on how the urban landscape affects the quality of life there. Urban dwellers spend the majority of their time indoors [2] and contact with the outside world is mostly limited to what they can see through their window. Hence, the quality of life of urban dwellers is associated with the visual quality of their windowscapes. However, this raises the question "how do we measure the visual quality of landscape in an urban context'?

Assessing preferences for natural landscapes is an established field of study. It is, however, not clear if findings from these studies are applicable to urban landscapes [3]. Moreover, there is relatively limited research on urban landscape preferences [4]-[8]. Two reasons account for the lack of research 
in this area. First, urban areas have highly complex structures, which makes assessing preference determinants difficult. Second, there are significant shortcomings with methods that have been used in studies of natural landscape preferences and hence it is necessary to question their applicability for studying urban landscapes.

Most studies into landscape preference have used experiments in a laboratory setting consisting of showing participants photographic images of scenes. Thus the experimental subjects did not have the holistic experience of the landscape, itself [9], [10]. Stamps [11] has identified over 1300 references that used photographs to evaluate landscape preference. Hence, very little is known on how real places are experienced [12]-[14], [10].

The method of asking people to rate photographs of the scenes cannot capture the subjective value of the urban landscape as experienced on a daily basis. In addition, "a photograph is totally unable to convey the life of the scene; [being] unable to discriminate; it merely records everything at one instant" [15, pp. 360-361]. Dearden [16] and Zube, Pitt, and Anderson [17] warn researchers to be cautious in their use of photographs and emphasise that photographs and actual environments are not completely interchangeable. Uzzell [18, p. 9] adds, "[i]t seems highly likely that the preferences expressed on the basis of two-dimensional photographs are different to those which might be made in situ". As Wohlwill [19] has rightly pointed out, a photograph cannot capture the ambience of an urban environment, which is composed of sonic and dynamic components as well as visual.

Although the results concerning validity of using photographs are inconsistent [11], [12], [20], [21]; much research in landscape preference continues to use static images. Research on urban landscapes has shown that urban images containing natural features (vegetation and water) are liked better than those without [22]-[25]. The presence of water features in urban landscapes is also found to have a positive effect on the economic values of properties [26]-[28]. However, open questions remain as to whether such results hold for actual scenes seen on a daily basis, and whether all natural features are equally preferred. Moreover, it is not yet clear how to combine common natural and built features to predict preference for urban landscapes.

This paper addresses the aforementioned limitations and gaps, with the objective of developing a novel method for measuring the visual quality of an urban landscape in a real context. Hence, the main research questions are:

1) How do urban dwellers perceive the visual quality of their everyday landscapes? and,

2) How to measure their urban landscape preferences in a real context?

The significance of this research rests on the fact that preferences reflect how well the given environments support well-being (e.g. [29], [30]). Research on the impact of landscape preferences on wellbeing has shown that an attractive windowscape is more than an amenity and underpinning this preference is a fundamental issue of psychological well-being and physical comfort [31], [32]. For instance, a cross-sectional survey on office workers in the Netherlands showed that attractive window views reduced discomfort (e.g. concentration problems and headache) [33]. A study by Lottrup and his colleagues showed that a view of natural elements was related to high view satisfaction, which then contributes to high work ability and high job satisfaction [34]. An archival study of past residents of a nursing home revealed a significant negative correlation between people view (view to parking lots, the front entrance, or a yard) and length of stay, while view of greenery had no effect on this matter [35]. 
Being able to identifying environmental characteristics, which can contribute to the enhancement of the visual quality of urban areas, will also be useful to policy makers, architects, urban planners, and environmental experts [36]. The results can help architectural and urban designers to provide urban environments, which promote psychological well-being.

\section{ACTIVE PERCEPTION TECHNIQUE: AN OVERVIEW OF THE ORIGINAL METHOD}

The central idea of the theoretical framework stems from research in environmental cognition, which claims that the real world is too complex to be processed completely by inhabitants. Hence, people create their own version of reality by selecting only those environmental features that produce affective responses. In this present work, it is similarly argued that viewing an urban landscape on a daily basis makes some features stand out more than others (depending on environmental and personal factors). Preferences held for these prominent perceptual features are proposed to be the determinants of preference for the overall landscape. The Active Perception Technique (APT) aims to capture these features and to explore the relationship between visual-quality values of these features and the overall view. As opposed to using photographs for environmental sampling, APT uses 'windowscapes viewed on a daily basis' as a convenient, useful tool. The main advantage of using window-views is the possibility to study the urban landscape in its real-context from the point of view of a building occupant.

APT originates from Kevin Lynch's [37] seminal work, 'Image of the City', and Nasar's [38] study, 'The Evaluative Image of the City'. Because he was interested in how people make sense of the vast amount of visual information in a city, Lynch [37] asked research participants to draw a quick sketch of their city as if they were making a rapid description of the city to a stranger. Lynch's analysis predominantly dealt with the effects of physically perceptible objects and the relation between image and physical form. He [37, p. 6] proposed the concept of environmental image, a generalized mental picture of the exterior physical world:

Environmental images are the result of a two-way process between the observer and his environment. The environment suggests the distinctions and relations, and the observer...selects, organizes, and endows with meaning what he sees. The image so developed now limits and emphasizes what is seen, while the image itself is being tested against the filtered perceptual input in a constant interacting process. Thus, the image of a given reality may vary significantly between different observers.

Nasar [38, p. 42] argued "evaluation is central to our perception of and reaction to the environment" and Lynch's theory of the city image can be strengthened by measuring the emotional meaning that an individual brings to the image. Nasar asked residents of two cities to identify areas that they liked visually and areas they disliked, and to describe the physical features accounting for their evaluation.

Nasar's concept of likability was used to develop the APT. The term likability refers to "the probability that an environment will evoke a strong and favourable evaluative response among the groups or the public experiencing it" [39, p. 3]. Likability derived from what Gibson has labelled affordance - the reciprocal relation between environmental properties of things and the active perceiver [40]. For instance, a road affords (supports) walking or driving. According to Nasar (1990), 
likability has two components imageability and affect. In other words, "for a favourable image, features must stand out as both memorable and likable" [39, pp. 60-61]. APT, accordingly, is composed of two parts:

- Capturing the imageable features of urban windowscape,

- Determining preferences for those features and their influence on overall windowscape preference.

Research participants were asked to sketch from memory what they could recall of the view from their window. It was stressed to the participants that their sketching technique was not important. They were asked to number each feature of the view in the order in which they had been drawn, to express their preferences towards them using the five-point Likert scale by annotating each with a letter: (A) for Strongly like, (B) for Like, (C) Not Sure, (D) for Dislike, and (E) for Strongly Dislike and to label these features. At the end, they were asked to rate their feelings towards the view in general using the same Likert scale. Participants were also instructed to 'label and number' each feature as they drew their sketches. Labelling the features ensure that differences in drawing ability do not

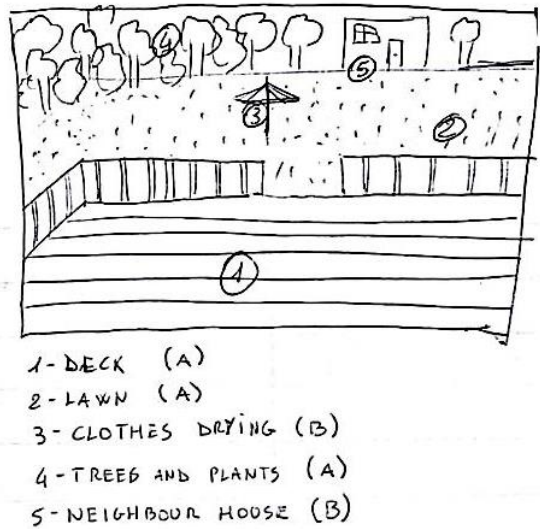

Figure 1 An example of data collected confound sketch output and consequently the result of the study. Figure 1 shows an example of data collected. This view was rated as Strongly Liked. These sketches were then compared against photos taken from the same viewpoint in order to compare the actual with the perceived view. At the end, participants were also asked to state some demographical information such as their age, gender, ethnicity and urban background.

\subsection{Participants}

The method is demonstrated by studying postgraduate students of two Auckland universities. A target population was identified as postgraduate research students, who had been assigned university workplaces in rooms with outdoor views. There is an advantage to using students as they have no vested interest in the workspace as employees might have (their response may impact on their job), and therefore the answers tend to be more objective. It was decided to use postgraduate students because they are the only students who are usually assigned workplaces at universities and spend most of their times within their workplaces.

Due to the qualitative nature of the study, participants were not expected to constitute a representative sample. However, individuals with different ethnicity and educational backgrounds and genders were recruited. As the research progressed, additional participants were recruited by purposeful sampling in order to achieve desired diversity of urban backgrounds.158 postgraduate research students were interviewed. The gender distribution of the survey was well balanced with $51 \%$ female and 49\% male. Most of the participants were in the age group of 26-35 (93 students, 59\%); followed by the group $<26$ (48 students, $30 \%$ ) and $11 \%$ were above the age 35 . The study participants were ethnically diverse (32\% Far East, $43 \%$ of European origin, $13 \%$ Middle East, $12 \%$ other). In terms of urban background, participants are fairly well distributed, with $53 \%$ lived most of their childhood in 
standalone houses within village, suburbs and towns and the rest lived in apartments within cities or mega-cities and had no access to private gardens.

Participation in the study was not limited to a particular university building or campus. However, $86 \%$ of the participants were based on the University of Auckland city campus, while the rest distributed among six different campuses around the city. Participants were mostly from the faculties of Science (24\%), National Institute of Creative Arts and Industries (NICAI) (22\%), Engineering (16\%) and Bioengineering Institute (12\%). The low response from postgraduate students in the University of Auckland Business School is due to the school policy that the research advertisement could only be distributed through the School Facebook page. The view of the participants from their offices were diverse depending on the location of the buildings in the campus and their rooms/desks within that buildings.

\section{$2.2 \quad$ Procedure}

Face-to-face questionnaire-based interview sessions were used as a tool for data collection. The participants were self-selected volunteers following advertisement of the aims and objectives of the project. Recruitment was achieved by invitation via fliers, emails, Facebook, and universities' newsletters, or group presentation in the postgraduate student meetings. All those who responded to advertisements or submitted their email addresses were contacted to schedule a date and time for an interview.

Participants were presented with a regular lead pencil, eraser, and a set of coloured pens for the sketching aspect of the survey. No rules or guidance on how to draw mental images were given to the participants. The only restriction was that the image should not be copied from the outdoor view but drawn from memory. Participants were also supervised to ensure that they would not look out of their office window while drawing. If a lack of confidence with drawing skills were observed by the researcher or expressed by participants themselves, writing down the name of features instead of drawing them was allowed. However, only one participant chose to write some of the features names under her sketch without drawing them.

For the office-view sketches, participants were advised to draw the view they could see when they were sitting behind their desks. For the house views the choice of view was more complicated since the variety of participants' living situations meant that several had access to more than one window in their homes. In these cases, participants were advised to choose between their bedroom and living room view, to represent the one in which they spend most of their time. Participants were encouraged to talk freely during sketching. The interview typically took 20 to 30 minutes to complete. Photos were taken of their office window views by the first author, and the participants were requested to email the photos of home views.

Photographs still play a role as a research instrument in this study; however, the approach to the use of photographs is different from photo protocol studies, which sees photos as a reasonable surrogate of the physical environment. In this research, a photograph is considered as an objective, definite of the view outside the window. Photographs capture exactly what is there to be seen and are compared against sketches to gain insight into the differences between the objectiveness of the environment and the subjective way of seeing the windowscape (or reconstructed image of the view).

The majority of interviews were conducted between July and August; only 19\% were held between November and December. Initially, it was intended to repeat the study in the opposite season. 
As the data collection started and progressed in wintertime, it was noticed that trees and greenery were drawn as if they still had leaves and/or flowers present. Absence of seasonal variation might be because sketches were drawn from memories. Based on this observation, it was decided to cancel the follow-up interview sessions.

\subsection{Analysis}

Following the data collection, all sketches were scanned, and a digital library built by placing sketches and the corresponding photographs next to each other on one page using Adobe Photoshop CS6. To avoid identification, all respondents are referred to by code numbers. The montage collection of sketches and photographs together with participants' socio-demographic datasheet were then uploaded into NVivo 10 for content analysis. NVivo is a qualitative data analysis software program designed "to manage, access and analyse qualitative data and to keep a perspective on all of the data, without losing its richness" [41].

Content analysis is an empirically grounded method, which has been widely used in the studies involving with visual data [42], [43]. The purpose of using content analysis was to identify the most common features within the views (e.g. trees, street, buildings). Frequency data generated by content analysis was analysed using SPSS. Statistical comparison was done by non-parametric methods (Mann Whitney U-test). For the statistical data analysis, responses were recorded as $A=5, B=4, C$ $=3, D=2$, and $E=1$. A p-value less than 0.05 was considered significant for all tests.

\section{RESULTS AND DISCUSSION}

The dataset comprises 158 respondents, 153 office-view sketches and 157 home-view ones, and 304 corresponding photos of the views. Missing data is because either a few participants did not have access to windows from their workplaces $(n=5)$ or their places of residence $(n=1)$, or

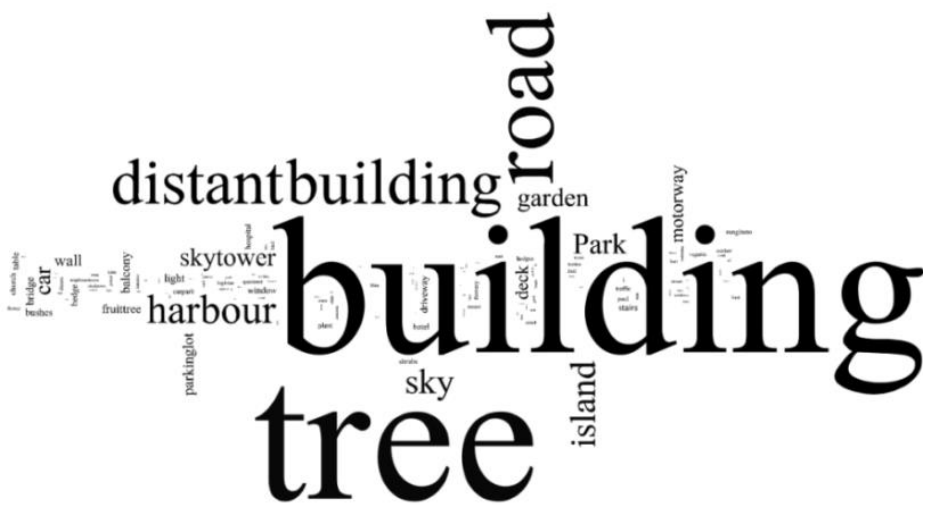

Figure 2 Word cloud made of words from features drawn/labeled in the sketches

they did not email their home-view

photographs $(n=6)$. On average four features were drawn in each sketch, and the results presented here are obtained from the analysis of more than 1240 drawn features.

The collected data covers a variety of Auckland windowscapes. The majority of window views provided visual access to some form of greenery (88\%). 57 participants could see parklands from their windows; while $13 \%$ of the home and office views were completely blocked by building(s) located immediately outside the windows $(n=39)$. Roading such as motorways, streets, roads, and driveways was visible from 103 of the window views and parking lots were identified in 25 sketches.

In order to find the most common windowscape features, all drawn and labelled features were compiled in an Excel spreadsheet and imported into NVivo. NVivo was set to group similar features together: e.g. road(s) or street(s) were merged into the word road. The results of this analysis using a word cloud of the phrases in which font size is associated with relative frequency are shown in Figure 2Error! Reference source not found.. Since the research was conducted in an urban area, it is not 
surprising that (distant) building appeared as the most frequently drawn and/or labelled features of the views. This was followed by tree, road, harbour, the sky, and island respectively.

A summary of the preferences for each windowscape feature is presented in Error! Reference source not found.. The percentage is calculated by counting how each feature is rated on the Likert scale (e.g. 'Strongly Like') and dividing them by the total numbers the feature appeared in the sketches. In this figure, the term 'Blocking Building' describes a building located immediately outside a window, which interrupted the lines of sight.

A straightforward result of this analysis revealed that urban natural features were preferred over urban built ones. Large bodies of water and the sky were the most preferred features within urban windowscapes. Similar results were reported by Howley and O'Donoghue [44] who asked their survey respondents to rate a list of 14 landscape elements based on how much they like each of these on a 5 -point Likert scale. The researchers found that water bodies were the most liked landscape attribute, followed by hills/mountains.

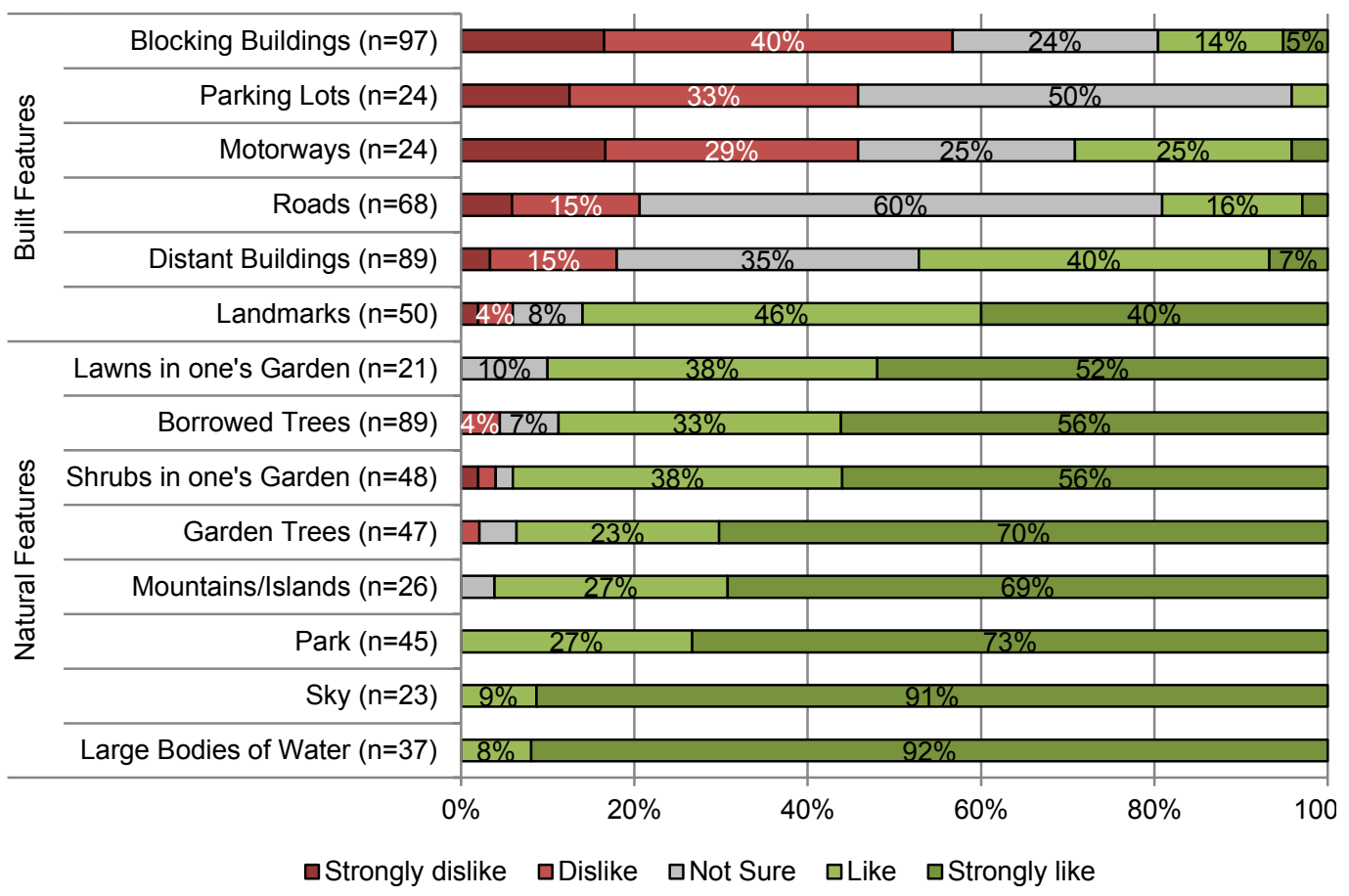

Figure 3 Feelings attached to the most common features of the view

Sky is the most under-researched feature in landscape studies as researchers using photoprotocol usually asked their respondents to rate the scenes without reference to the appearance of the sky (e.g. [45]). This is because the presence of sky in landscape photographs is more related to photocomposition and measuring its significance to landscape preference may not provide useful information using this method. However, APT reveals that the sky is considered as one of the most attractive features of urban landscapes. Preference to see the sky has been previously reported in a few windowscape studies (e.g. [46], [47]) and was linked to the preference to see the weather out of the window [47].

'Park land' was the most-preferred type of greenery rated by $73 \%$ as strongly like, followed by garden trees (rated strongly liked by $70 \%$ ). The respondent's own lawns were the least preferred 
feature in urban natural category. This finding was in line with the results of a study on workplace window-views which found that flowers, trees, and park-like environment increased the odds of being satisfied with the views, however, no significant relationship was found between view satisfaction and presence of 'mowed lawns' [48]. The difference in preferences of tree and grass might be because the visual effect of trees is three-dimensional [49], and that they are relatively uncontrolled in their form (no straight edges). Instrumental functions of urban trees, shade and shelter, can also explain the reasons why trees are valued more than lawns (Gibson's [40] affordances).

One of the interesting and novel results obtained from the APT application was finding that personal association had an impact on preferences for greenery. For instance, the percentage of the respondent's garden trees rated as 'strongly like' was higher than borrowed (street or neighbour's) trees. Moreover, comparing photographs with sketches, all twenty-six participants, who could also see greenery outside of their garden, omitted it from their sketches (see Figure 4 for example). Street trees were positively rated on the Likert scale; however, median preference score for views with street trees $(M d n=4)$ and without trees $(M d n=4)$ were not statistically different, U-test=11537.5, $z=-.45, n s$. This result suggests that although street trees are visually valued, they are not as powerful as photoprotocol studies suggest in affecting preference visual quality of the urban landscape.
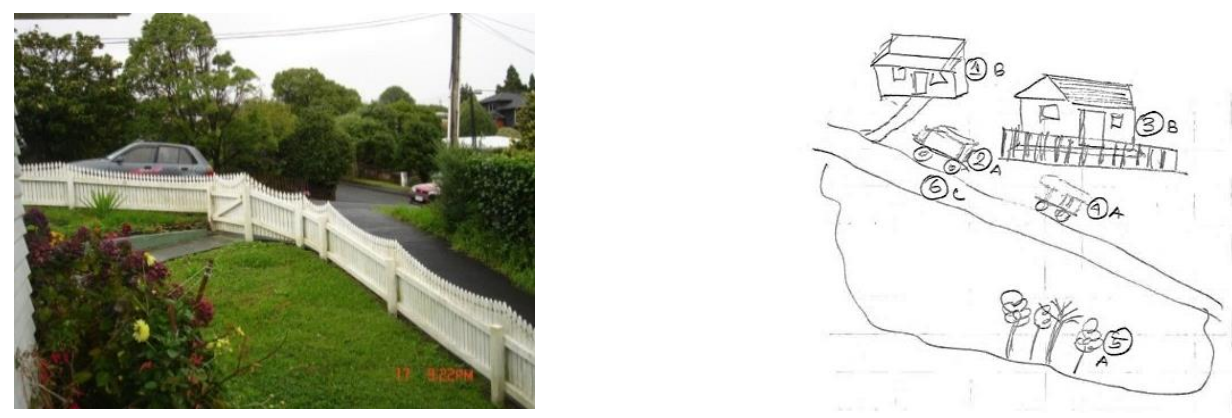

Figure 4 Omission of greenery that was located outside one's garden

Landmarks comprise those features in the sketches that were labelled and rated separately from other 'distant buildings' (buildings that were located in the far distance of the views) indicating that, in the eyes of the observer, they stood out from other buildings. These features are namely Auckland War Museum, Sky Tower, Harbour Bridge, Auckland City Hospital. Landmarks were the most preferred built features, rated as 'strongly like' or 'like' by $86 \%$ of participants. Landmarks were drawn with clear exaggerations (Figure 5) even when their silhouette was only visible on the horizon, suggesting their significance as an urban feature. Herzog, Kaplan, and Kaplan's [50] study on familiar urban places revealed that pictures depicting cultural buildings (e.g. churches, an art museum) were relatively high in preference.
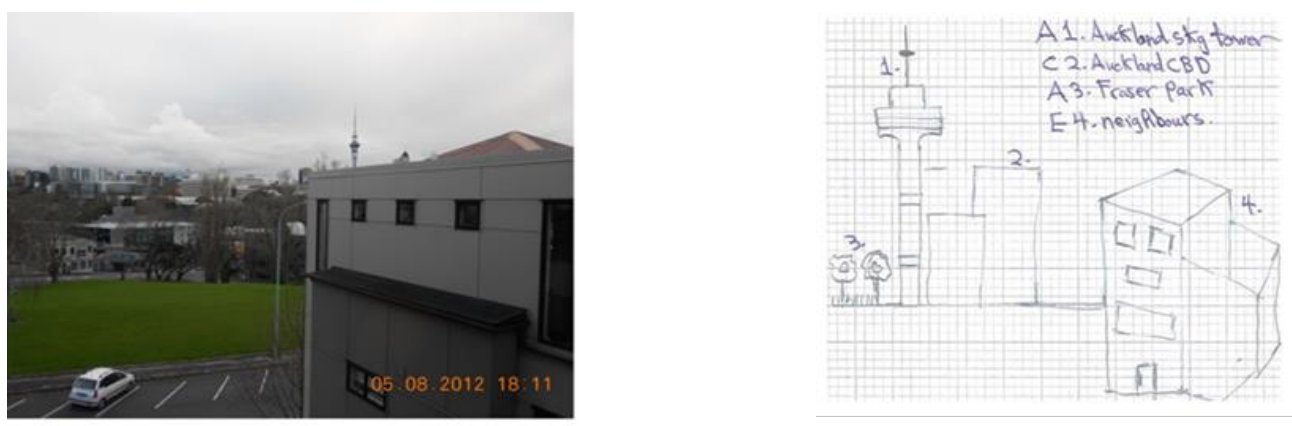

Figure 5 The exaggeration of sky tower in comparison to the photo from the view window. 
Parking lots and motorways created negative preferences in $46 \%$ of observers. The majority $(60 \%)$ were indifferent to the presence of roads within their views. However, it was found that the percentage of roads negatively scored on the Likert scale was larger and significantly different in home views $(33 \%)$ than in office views $(9 \%), U$-test=390.5, $z=-2.615, p<0.01, r=-.22$. Such a result is not surprizing as the research conducted in real setting and aural components of the urban landscape can have an impact on visual preferences. In particular, we believe that a higher need for acoustic privacy in residential places did not let the participants of our study judge the roading based purely on visual contribution.

Blocking buildings (that were located in the immediate foreground of the views) were the least preferred feature with $56 \%$ rating them as disliked or strongly disliked. Similarly, a study on view preferences on human-made islands reported that the presence of residential buildings at a close distance were the most important determinants of a negative assessment of the view [51]. Herzog found that blocked urban scenes were rated lower in preference than photos depicting well-structured scenes with an intermediate level of openness [52].

\subsection{The Effect of Features on Windowscapes Preferences}

This section investigates whether the presence of each feature within a view has any influence on the overall preferences for the view. The window views are categorised into four preference categories (strongly liked views, liked views, indifferent to the views and strongly disliked \& disliked views) depending on how the overall view have been rated by the participants. As only four windowscapes were rated as Strongly Disliked; it was decided to merge them into the Disliked category.

An analysis of the frequency of the appearance of features in each preference category was carried out with the aim of determining if a combination of common urban features can be found for making predictions about windowscape preferences. For this analysis, all the features that appeared in windowscapes rated as 'strongly like', for instance, were listed in a spreadsheet, and uploaded into NVivo. The result of this analysis is presented in Table 1. The percentage is calculated by dividing the number of times each feature appeared in a view preference category by the total number of features within that category.

Looking at Table 1, it is clear there are more features within the word clouds of 'strongly like' window-views compared to the ones in 'strongly dislike' \& 'dislike' categories. This difference is because complexity, the average number of features in the view, has an influential factor on view preferences [46], [53]. As the research mainly involved an urban situation, the presence of buildings within the views was inevitable. Accordingly, it is not surprising that blocking and distant buildings appeared in all types of windowscape with different preference scores. The percentage of the times Blocking Building(s) appeared in strongly disliked and disliked views is significantly higher than the times this feature is drawn in the preferred views. In contrast, the number of times distant buildings are noted in the participants' sketches increases with increased preference for the views. This increase reaches the point where buildings in the far distance were more frequently mentioned in the strongly liked category than buildings in the foreground. This finding should not be taken to mean that the appearance of distant buildings positively affects preferences for windowscapes. Since this research was conducted in an urban area, the presence of distant buildings merely indicates that these windowscapes were offering long views. The presence of road networks (driveway, road/street, 
motorway) in the views also seems to be a determining factor in windowscape preferences. As can be seen, there is a correlation between the percentage of the time natural features are mentioned in the views and preferences for the view. However, each natural feature seems to have a different power in affecting the windowscape preferences. For instance, own garden trees or the Park land have only appeared in the word clouds of liked and strongly liked categories, suggesting that their appearance is likely to be associated with positive preferences of the views. Borrowed trees, however, appeared in all the word clouds, which do not seem to be associated with windowscape preference. This finding supports the result (see Figure 3) suggesting that borrowed trees are one of the least preferred features of urban greenery.

Table 1 Frequency of each features appeared in each window views preference category

\begin{tabular}{|c|c|c|c|c|c|c|c|c|}
\hline \multirow[t]{2}{*}{ Rank } & \multicolumn{2}{|c|}{$\begin{array}{l}\text { Strongly Disliked \& } \\
\text { Disliked Views }(n=77)\end{array}$} & \multicolumn{2}{|c|}{$\begin{array}{l}\text { Indifferent to the Views } \\
(n=82)\end{array}$} & \multicolumn{2}{|l|}{ Liked Views ( $n=269)$} & \multicolumn{2}{|c|}{ Strongly liked Views $(n=220)$} \\
\hline & Features & $\%$ & Features & $\%$ & Features & $\%$ & Features & $\%$ \\
\hline 1 & Blocking Building & $43 \%$ & Blocking Building & $32 \%$ & Distant Building & $22 \%$ & Distant Building & $26 \%$ \\
\hline 2 & Road Networks & $22 \%$ & Borrowed Trees & $18 \%$ & Road Networks & $16 \%$ & Own (Garden) Trees & $12 \%$ \\
\hline 3 & Borrowed Trees & $19 \%$ & Distant Building & $18 \%$ & Blocking Building & $14 \%$ & Borrowed Trees & $11 \%$ \\
\hline 4 & Distant Buildings & $10 \%$ & Road Networks & $17 \%$ & Borrowed Trees & $13 \%$ & Harbour & $10 \%$ \\
\hline 5 & Parking Lot & $5 \%$ & Parking Lots & $7 \%$ & University Owned Tree & $11 \%$ & Domain Park & $10 \%$ \\
\hline 6 & & & Sky & $7 \%$ & Domain Park & $9 \%$ & Road Networks & $9 \%$ \\
\hline 7 & & & & & Own (Garden) Trees & $7 \%$ & Sky & $8 \%$ \\
\hline 8 & & & & & Parking Lots & $5 \%$ & University Owned Trees & $8 \%$ \\
\hline 9 & & & & & Lawns & $3 \%$ & Lawns & $5 \%$ \\
\hline & & $100 \%$ & & $100 \%$ & & $100 \%$ & & $100 \%$ \\
\hline
\end{tabular}

\section{CONCLUSIONS}

This study uses a novel method for measuring urban landscape preferences from the point of view of daily observers. Active Perception Technique (APT) consists of collecting information from a brief sketch, a questionnaire, and a windowscape photograph. APT allowed participants to engage actively with their views by drawing what they could recall seeing out of their windows. Photographs still play a role as a research instrument in this study, though the use differs from photograph study protocols. Traditional protocols see photographs as a reasonable surrogate of the physical environment. In this research, photographs are considered to be tools, as an objective record of the view outside. Photographs capture exactly what is there to be seen, and a comparison between photographs and sketches indicates how a person perceives the view, which can contrast greatly with the reality documented in the photograph.

Participants in this study had visual contact with a view on a daily basis; therefore, the results reveal the reaction of participants to a three-dimensional, ever-changing environment. Results obtained from APT have a clear potential to be useful for policy makers, and planners to enhance visual quality of built environments and to provide more likable and liveable cities. It may also have an economic impact on the value of buildings. This has already been demonstrated for water views [27], [28]; so why not for preferred landscapes. It can also help to identify particularly influential features of urban landscape preference, and hence aid in the development of guidelines for improving the visual quality of cities. For instance, in this study it was found that trees that were owned by observers evoked a stronger positive effect than street trees. Therefore, it may be a better choice to leave maintenance of street trees in residential areas to the local community who are willing to undertake such 
responsibility. In this case, the local council should inspect the street trees occasionally to ensure that the trees are well maintained.

Since APT was tested using only postgraduate students, we have no proof of the generalizability of our results. However, one of the principal objectives of this work was to show the applicability of the technique; the representativeness of the research sample was not a priority. Although tertiary students (mainly undergraduate students) have been widely used as participants in surveys of landscape preferences studies (see [54] and [55] for detail reviews); researchers did not reach a consensus if students can satisfactorily substitute for the general public (cf. [56] and [57]). Participants of the present research were overwhelmingly young $(<35,89 \%)$ and highly educated (73\% Ph.D. students). The generalizability of conclusions drawn from results of the study may well be somewhat limited by differences in level of education, age group and the relatively small number of individuals interviewed. Note especially that there is some evidence that age [21] and level of education (e.g. [58]) seem to affect landscape preferences.

The external validity (generalizability) of the study findings is also limited by 1) the findings only represented the landscape preferences of those postgraduates who had access to window views in their office and/or home; 2) the possibility that those postgraduate students who were more satisfied with their views might have volunteered to participate in the study. The current work would benefit by being repeated in different population groups.

Although this study demonstrated the method in the urban landscape, APT has a great potential to be used as a decision tool in cultural landscape management. For instance, as cities intensify one of the challenges in management of urban cultural landscapes is what to conserve. APT can help to identify significant cultural features in an urban environment; also, can justify preserving existing view shafts to these features as the city intensifies. APT can also be used to understand whether urban landscape quality have any influence on health and well-being of the observers. This can be done for instance by asking the observers to rate their perceived health or expose whether they have been diagnosed with any health issues in the last year or so.

Research has shown that in addition to physical characteristics of the landscape, observers' demographic characteristics can have an influence on windowscape preferences. Current research has found similar results revealing that the urban background and gender can have influence on preferences of urban landscape; in particular blocked views. However, these results will be presented in the future publications.

In this research, a homogeneous group (postgraduate students) were chosen to demonstrate the method. However, APT could be used to show differences in landscape preferences between differing groups, sub-cultures, and special populations. For instance, APT can compare preferences of tourists and local residents, which can guide urban planners and policy makers when allocating land to residential and touristic uses. APT could be a tool for evaluating the difference between social and cultural landscapes and showing strengths and weaknesses of the visual quality of each. Such information can be used to improve the appearance of urban areas and make a more pleasant place to live.

Although preference may compass other visual dimensions of urban cultural landscapes such as tranquillity and security, APT can be modified to measure these aspects too. For instance, APT can 
provide useful information about tranquillity values of visual contact with some cultural heritage such as mosques or churches.

\section{ACKNOWLEGMENTS}

The authors would like to acknowledge the advice of Dr Michael Linzey and Dr George Dodd.

\section{REFERENCES}

[1] M. Déjeant-Pons, "The European Landscape Convention," Landsc. Res., vol. 31, no. 4, pp. 363-384, 2006.

[2] C. A. Shoemaker, Ed., Interaction by Design: Bringing People and Plants Together for Heatlh and Well-Being, 1st ed. Wiley-Blackwell, 2002.

[3] R. Home, N. Bauer, and M. Hunziker, "Cultural and Biological Determinants in the Evaluation of Urban Green Spaces," Environ. Behav., vol. 42, no. 4, pp. 494-523, Jul. 2010.

[4] M. P. Galindo and M. C. Hidalgo, "Aesthetic preferences and the attribution of meaning: Environmental categorization processes in the evaluation of urban scenes," Int. J. Psychol., vol. 40, no. 1, pp. 19-27, 2005.

[5] M. C. Hidalgo, R. Berto, M. P. Galindo, A. Getrevi, M. Ambiente, and C. Humano, "Identifying attractive and unattractive urban places: categories, restorativeness and aesthetic attributes," Medio Ambiente Comport. Hum., vol. 7, no. 2, pp. 115-133, 2006.

2012.

[6] I. C. Kaymaz, "Chapter 12: Landscape Perception," in Landscape Planning, InTech,

[7] R. Crane and R. Weber, The Oxford Handbook of Urban Planning. Oxford University

Press, 2012.

[8] H. Hellinga, "Daylight and View: The influence of windows on the visual quality of indoor spaces," PhD thesis, Delft University of Technology, 2013.

[9] M. V. Giuliani and M. Scopelliti, "Empirical research in environmental psychology: Past, present, and future," J. Environ. Psychol., vol. 29, no. 3, pp. 375-386, Sep. 2009.

[10] C. W. Thompson, "Landscape perception and environmental psychology," in The Routledge Companion to Landscape Studies, Routledge, 2013.

[11] A. E. Stamps, "Use of Photographs to Simulate Environments: A Meta-Analysis," Percept. Mot. Skills, vol. 71, no. 3, pp. 907-913, Dec. 1990.

[12] R. B. Hull IV and W. Stewart, "Validity of photo-based scenic beauty judgments," J. Environ. Psychol., vol. 12, no. 2, pp. 101-114, Jun. 1992.

[13] P. H. Gobster, "An Ecological Aesthetic for Forest Landscape Management," Landsc. J., vol. 18, no. 1, pp. 54-64, Mar. 1999.

[14] M. S. Myers and C. W. Thompson, "Chapter 3: Interviews and Questionnaires," in Crossplan: Integrated, participatory landscape planning as a tool for rural development, Simon Bell, Ed. Edinburgh: Forestry Commission, 2003, pp. 17-29.

[15] D. C. D. Pocock, "Valued Landscape in Memory: The View from Prebends' Bridge," Trans. Inst. Br. Geogr., vol. 7, no. 3, pp. 354-364, Jan. 1982.

[16] P. Dearden, "Landscape Assessment: The Last Decade," Can. Geogr. Géographe Can., vol. 24, no. 3, pp. 316-325, 1980.

[17] E. H. Zube, D. G. Pitt, and T. W. Anderson, "Perception and prediction of scenic resource values of the Northeast.," 1975.

[18] D. L. Uzzell, "Environmental psychological perspectives on landscape," Landsc. Res., vol. 16, no. 1, pp. 3-10, Mar. 1991.

[19] J. F. Wohlwill, "Environmental aesthetics: the environment as source of affect," in Human Behavior and Environment, New York: Plenum, 1976, pp. 37-86.

[20] T. C. Daniel and M. M. Meitner, "Presentational Validity of Landscape Visualizations: The Effects of Graphical Realism on Precieved Senic Beauty of Forest Vistas," J. Environ. Psychol., vol. 21, no. 1, pp. 61-72, Mar. 2001.

[21] E. H. Zube and D. G. Pitt, "Cross-cultural perceptions of scenic and heritage landscapes," Landsc. Plan., vol. 8, no. 1, pp. 69-87, Feb. 1981.

[22] T. R. Herzog, "A cognitive analysis of preference for urban nature," J. Environ. Psychol., vol. 9, no. 1, pp. 27-43, 1989.

[23] V. L. Sheets and C. D. Manzer, "Affect, Cognition, and Urban Vegetation Some Effects of Adding Trees Along City Streets," Environ. Behav., vol. 23, no. 3, pp. 285-304, May 1991. 
[24] M. White, A. Smith, K. Humphryes, S. Pahl, D. Snelling, and M. Depledge, "Blue space: The importance of water for preference, affect, and restorativeness ratings of natural and built scenes," J. Environ. Psychol., 2010.

[25] E. V. White and B. Gatersleben, "Greenery on residential buildings: Does it affect preferences and perceptions of beauty?," J. Environ. Psychol., vol. 31, no. 1, pp. 89-98, Mar. 2011.

[26] J. J. Kim and J. Wineman, "Are windows and views really better? A quantitative analysis of the economic and psychological value of views," Rep. Univ. Mich., 2005.

[27] O. E. Samarasinghe and B. M. H. Sharp, "The value of a view: A spatial hedonic analysis," N. Z. Econ. Pap., vol. 42, no. 1, pp. 59-78, 2008.

[28] C. Y. Jim and W. Y. Chen, "Value of scenic views: Hedonic assessment of private housing in Hong Kong," Landsc. Urban Plan., vol. 91, no. 4, pp. 226-234, Jul. 2009.

[29] T. Hartig and H. Staats, "The need for psychological restoration as a determinant of environmental preferences," J. Environ. Psychol., vol. 26, no. 3, pp. 215-226, Sep. 2006.

[30] A. E. van den Berg, S. L. Koole, and N. Y. van der Wulp, "Environmental preference and restoration: (How) are they related?," J. Environ. Psychol., vol. 23, no. 2, pp. 135-146, Jun. 2003.

[31] Leather, P., Pyrgas, M., Beale, D., \& Lawrence, C. (1998). Windows in the Workplace: Sunlight, View and Occupational Stress. Environment and Behavior, 30(6), 739-762.

[32] Tuaycharoen, N., \& Tregenza, P. R. (2007). View and discomfort glare from windows. Lighting Research and Technology, 39(2), 185-200.

[33] Aries, M. B. C., Veitch, J. A., \& Newsham, G. R. (2010). Windows, view, and office characteristics predict physical and psychological discomfort. Journal of Environmental Psychology, 30(4), 533-541.

[34] Lottrup, L., Stigsdotter, U. K., Meilby, H., \& Claudi, A. G. (2013). The Workplace Window View: A Determinant of Office Workers' Work Ability and Job Satisfaction. Landscape Research, $0(0), 1-19$.

[35] O'Connor, B. P., Davidson, H., \& Gifford, R. (1991). Window View, Social Exposure and Nursing Home Adaptation. Canadian Journal on Aging/La Revue Canadienne Du Vieillissement, 10(03), 216-223.

[36] L. E. Jackson, "The relationship of urban design to human health and condition," Landsc. Urban Plan., vol. 64, no. 4, pp. 191-200, Aug. 2003.

[37] K. Lynch, The Image of the City. Cambridge [Mass.]: Technology Press, 1960.

[38] J. L. Nasar, "The Evaluative Image of the City," J. Am. Plann. Assoc., vol. 56, no. 1, pp. 41-53, Mar. 1990. 1998.

[39] J. L. Nasar, The evaluative image of the city. Sage Publications Thousand Oaks, CA,

[40] J. J. Gibson, The Ecological Approach to Visual Perception. Routledge, 1986.

[41] Bazeley, P., \& Richards, L. (2000). The Nvivo Qualitative Project Book. SAGE.

[42] P. Bell, "Content Analysis of Visual Images," in Handbook of visual analysis, London; Thousand Oaks [Calif.]: SAGE, 2001, pp. 10-35.

[43] R. Maggi and C. Scholz, "Finding the Invisible-Quantifying the 'urban beauty'of Dubai via content analysis of photographs," in Instant Cities: Emergent Trends in Architecture and Urbanism in the Arab World., UAE, 2008.

[44] P. Howley and C. O'Donoghue, "Landscape preferences and residential mobility: Factors influencing individuals' perceptions of the importance of the landscape in choosing where to live," J. Landsc. Stud., vol. 4, no. 1, 2011.

[45] R. G. Ribe, E. T. Armstrong, and P. H. Gobster, "Scenic Vistas and the Changing Policy Landscape: Visualizing and Testing the Role of Visual Resources in Ecosystem Management," Landsc. J., vol. 21, no. 1, pp. 42-66, Jan. 2002.

[46] T. A. Markus, "The function of windows- A reappraisal," Build. Sci., vol. 2, no. 2, pp. 97-121, Jun. 1967.

[47] H. Hellinga and G. de Bruin-Hordijk, "Preferences of office workers regarding the lighting and view out of their office," in SOLG Symposium Light, Performance and Quality of Life, 2008, pp. 26-29.

[48] L. Lottrup, U. K. Stigsdotter, H. Meilby, and A. G. Claudi, "The Workplace Window View: A Determinant of Office Workers' Work Ability and Job Satisfaction," Landsc. Res., vol. 0, no. 0, pp. 1-19, 2013.

[49] Y. Aoki, Y. Yasuoka, and M. Naito, "Assessing the impression of street-side greenery," Landsc. Res., vol. 10, no. 1, pp. 9-13, 1985.

[50] T. R. Herzog, S. Kaplan, and R. Kaplan, "The Prediction of Preference for Familiar Urban Places," Environ. Behav., vol. 8, no. 4, pp. 627-645, Dec. 1976.

[51] I. Z. Kfir, J. Munemoto, O. Sacko, and Y. Kawasaki, "Evaluation of the view from the dwelling units on man made islands in Osaka bay. Multiple regression analysis based on residents' 
evaluation and image processing of photographs taken from the living room.," J. Archit. Plan. Environ. Eng., no. 554, pp. 357-364, 2002.

[52] T. R. Herzog, "A cognitive analysis of preference for urban spaces," J. Environ. Psychol., vol. 12, no. 3, pp. 237-248, 1992. 1975.

[53] B. L. Collins, "Windows and people: A literature survey," NBS Build. Sci. Ser., vol. 70,

[54] Lothian, A. (2000). Landscape Quality Assessment of South Australia (PhD Thesis), University of Adelaide.

[55] Stamps, A. E. (1999). Demographic Effects in Environmental Aesthetics: A MetaAnalysis. Journal of Planning Literature, 14(2), 155-175.

[56] Tveit, M. S. (2009). Indicators of visual scale as predictors of landscape preference; a comparison between groups. Journal of Environmental Management, 90(9), 2882-2888.

[57] Yao, Y., Zhu, X., Xu, Y., Yang, H., Wu, X., Li, Y., \& Zhang, Y. (2012). Assessing the visual quality of green landscaping in rural residential areas: the case of Changzhou, China. Environmental Monitoring and Assessment, 184(2), 951-967.

[58] Vecchiato, D. (2012, February). Valuing landscape preferences with perceptive and monetary approaches: two case studies in Italy (Thesis). University of York. 


\title{
Dear Editor,
}

Thank you so much for reviewing our manuscript. We greatly appreciate the reviewers' kind words, comments and suggestions. We have revised the manuscript accordingly.

Please find below a point by point response to the reviewers' concerns. We hope that you find our responses satisfactory and the manuscript is now acceptable for publication.

Yours sincerely,

The Authors

\author{
Date: $\quad$ Oct 21,2019 \\ To: $\quad$ "Hugh Byrd" hbyrd@lincoln.ac.uk;leila.mirza@hotmail.co.nz \\ cc: marcusxgrant@citieshealth.world, s.milliken@greenwich.ac.uk \\ From: $\quad$ "Cities \& Health" rcah-peerreview@journals.tandf.co.uk \\ Subject: (Cities \& Health) A revise decision has been made on your submission
}

Oct 21, 2019

Ref.: Ms. No. RCAH-2019-0035

Measuring Biophilia in Cities: a Window onto Urban Landscapes

Cities \& Health

Dear Hugh,

Reviewers have now commented on your paper. You will see that they are advising that you revise your manuscript. If you are prepared to undertake the work required, I would be pleased to review a revision.

For your guidance, reviewers' comments are appended below.

If you decide to revise the work, please submit a list of changes or a rebuttal against each point which is being raised when you submit the revised manuscript.

Your revision is due by Nov 20, 2019.

To submit a revision, go to https://www.editorialmanager.com/citiesandhealth/ and log in as an Author. You will see a menu item called 'Submission Needing Revision'. You will find your submission record there.

Yours sincerely

Sarah Milliken, DPhil

Guest Editor

Cities \& Health

Reviewers' comments:

Reviewer \# 1: No additional comments.

\section{Reviewer \#2: Dear authors,}

I found your approach on assessing urban landscape quality very interesting and useful. Your approach is based on a perception analysis which is a good thing as landscape is strongly related to perception. These kinds of analysis are, however prone to subjectivism in relation with the perceiver. Nevertheless, the APT method is a step forward in achieving better results than the classical qualitative methods based on photographs analysis, fact very well emphasized throughout the paper. The idea of choosing two directions (workplace windowscapes and residential windowscapes) for your analysis is very good as landscape perception is strongly related with psychological factors that differ depending on the 
environment or context in which the perceiver is assessed. Of course, there is a wide range of places to be considered when assessing the urban landscape perception, but as it was stated in the paper, urban people spend a high amount of time indoors, thus the methods used in this study have a high degree of relevance.

[Reviewer \#2 - Comment 1] As the study being a perception analysis I would kindly recommend for your future studies to have a more sensitive attention towards the respondents profile. Considering that your paper aims in emphasizing a rather new approach in assessing urban landscape quality I find as enough the fact that, in regard with the respondents profile, you payed attention to the gender, ethnical and age aspects. However, there is not quite clear in your paper how do you consider these features to have an influence over the results, because they have. Therefore I kindly recommend that either in this paper or in future studies tackling similar topics to emphasize more the significance of the respondents profile over the perception analysis results. For instance, an important feature to be considered in the respondents profile would have been the period in which they where living in a city. We can agree on the fact that people born in rural areas or smaller towns, spending their childhood and teenage years in those areas might provide different perspective on landscape preferences than people born and raised in urban agglomerations or major cities.

Response: To address this comment following information is added to section 2.1 and section 4.

[Reviewer \# 2 - Comment 2] The "Conclusion" section of your paper was written in a straight forward approach, which is proper for the reader. However, I would have liked to see a more emphasise on how urban landscape quality is related with human health or general well-being. It would have been interesting if along or within the APT you asked the perceivers to expose if in the last year for instance they were diagnosed with any illness or how do they consider their health status. Then, a correlation, if any, with the windowscapes could have been revealing interesting results. As I acknowledged that this was not among the aims of the study I will not insist any more on the subject but I suggest to consider it for future researches.

Response: The following sentences are added to the conclusion section to address this comment:

"APT can also be used to understand whether urban landscape quality have any influence on health and well-being of the observers. This can be done for instance by asking the observers to rate their perceived health or expose whether they have been diagnosed with any health issues in the last year or so."

Overall, I consider your research paper to be suited for publication in this current form. However, if you feel the above comments to be of any value for improving the paper I would be pleased with theoutcomes.

\section{Reviewer \#4: Dear Authors,}

Thanks to the researchers for efforts they shown in this study. This work fits well within journal's aims and scope and appears to be an original contribution that could add to the body of knowledge in understanding landscape issues. However, this paper has a number of problems that prevent me from directly accepting this research for publishing. I am suggesting some revisions (major) for the authors, then this manuscript could be at publishable level. The revisions given to the authors are below mentioned:

[Reviewer \#4 - Comment 1] First of all, it is expected that a scientific study should contribute to science at universal scale. Therefore, in order for this study to be useful in universal scale, inferences should be extended in universal scale and suggestion section should be developed by taking the situation determinations made for the study field.

Response: We have tried to separate the universality of the 'method' with the specific nature of the 'case study' that validates it. The method could be used in most urban areas but the results are likely to differ depending on many factors including culture, climate and participant groups."

[Reviewer \#4 - Comment 2] The term of "Biophilia" is used only one time in the title of the manuscript! Either the title should be changed or explanations about this term should be added.

Response: The title is now revised to 'Measuring View Preferences in Cities: a Window onto Urban Landscapes'

[Reviewer \#4 - Comment 3] In abstract section, if the abbreviation (APT) is to be used in the text, the long version must be written in the first spelling.

Response: APT is now defined in the abstract.

It is also expected that a scientific study should be understood easily by the readers. In method section, some of the issues are not understandable and should be explained clearly. For instance;

[Reviewer \#4 - Comment 4] The participants were asked to put the features drawn in the drawings in order. At what stage and how was this ranking used? There is no explanation about this issue in the text.

Response: Further explanation about the ranking and labelling the features is added to section 2.

[Reviewer \#4 - Comment 5] At the beginning of page 4 ("They were also asked to..."), no information is provided 
in the article on the data for the evaluation of windowscapes mentioned.

Response: Section 3.1 of this manuscript is using the evaluation of windowscapes to identify the importance of each feature on view preferences. The following paragraph is now added for further clarification:

"This section investigates whether the presence of each feature within a view has any influence on the overall preferences for the view. The window views are categorised into four preference categories depending on how the overall view have been rated by the participants."

[Reviewer \#4 - Comment 6] In page 4 line 8, the fact that all the participants are individuals in the same group weakens the validity of the results.

Response: We agree with the reviewers comment and this issue has been already discussed in the conclusion section: "However, it should be mentioned that the results present postgraduate students' preferences and may not be transferred to the general public. The current work would benefit by being repeated in different population groups."

However below paragraph is added for further clarification:

"Since APT was tested using only postgraduate students, we have no proof of the generalizability of our results. However, one of the principal objectives of this work was to show the applicability of the technique; the representativeness of the research sample was not a priority. Although tertiary students (mainly undergraduate students) have been widely used as participants in surveys of landscape preferences studies (see Lothian (2000); Stamps (1999) for detail reviews); researchers did not reach a consensus if students can satisfactorily substitute for the general public (cf. Tveit (2009) and Yao et al. (2012)). Participants of the present research were overwhelmingly young $(<35,89 \%)$ and highly educated (73\% Ph.D. students). The generalizability of conclusions drawn from results of the study may well be somewhat limited by differences in level of education, age group and the relatively small number of individuals interviewed. Note especially that there is some evidence that age (Zube et al., 1983) and level of education (e.g. Vecchiato, 2012) seem to affect landscape preferences.

[Reviewer \#4 - Comment 7 In page 4 line 17, the determination of survey number (158) should be explained clearly in terms of statistical science. How was it calculated?

Response: Following paragraph is added in Section 2.1 to provide clarifications regarding the sampling:

"Due to the qualitative nature of the study, participants were not expected to constitute a representative sample. However, individuals with different ethnicity and educational backgrounds and genders were recruited. As the research progressed, additional participants were recruited by purposeful sampling in order to achieve desired diversity of urban backgrounds."

[Reviewer \#4 - Comment 8] In page 5 line 7, a brief information about the Nvivo 10 software should be given.

Response: This is now added to section 2.3

[Reviewer \#4 - Comment 9] In page 6 and 9, how the percentages in Figure 2 and Table 1 were calculated should be formulated and explained.

Response: Explanations is added to clarify how percentages are calculated in Figure 2 and Table 1

[Reviewer \#4 - Comment 10] In page 7, figure label could be shorter.

Response: Legend of Figure 4 is revised and shortened.

[Reviewer \#4 - Comment 11] In page 8 line 25-27 ("Blocking building is a prominent..."), the sentence should be revised, it is not understandable.

Response: The sentence is now revised to

"The percentage of the times Blocking Building(s) appeared in strongly disliked and disliked views is significantly higher than the times this feature is drawn in the preferred views."

[Reviewer \#4 - Comment 12] In page 9 Table 1, why were these two options in column 1 (Strongly Disliked \& Disliked Views) combined? They should be given separately, or an explanation should be given for the combination.

Response: Explanation is now given in Section 3.1

[Reviewer \#4 - Comment 13] In page 9 Table 1, it is thought that there may be errors in the calculation of percentages. For example, 65 of the total 601 "liked views" responses were received for 'blocking buildings', then the percentage of "liked views for blocking buildings" was calculated as $11 \%$. In my opinion, what needs to be done here; the percentage of the "liked view" response in the drawings with the corresponding feature should be calculated. (For example, suppose only 100 out of a total of 304 photos have blocking buildings feature, if 65 "liked views" responses are received in these 100 photos, the percentage should be $65 \%$, not $11 \%$ )

In page 9 Table 1, in the previous figure (Figure 2), $n=97$ is given for the distant building; but this number increases to the total of $n=190$ in Table 1 . What is the reason for this change? It should be explained. 
Response: The reviewer is correct and there were mistakes in the cross tabulations and analysing the data. We sincerely apologise for the mistakes. This Table is now revised, the numbers now correspond to the one in Figure 2 . We thank the reviewers for noticing this.

[Reviewer \#4 - Comment 14] In page 10, lines 24-25 ("Therefore, it may be a better choice..."), this suggestion could have some disadvantages. They should be evaluated and explained in discussion section.

Response: The sentence is now revised to point out the possible disadvantages of this suggestion.

[Reviewer \#4 - Comment 15] In page 10, line 42, the word "homogeneous" should be "heterogeneous". Because as mentioned before, all the participants are individuals from the same group.

Response: Thanks for the comment, but we still believe that the word 'homogeneous' is correctly used here. The word 'relatively' is removed from the sentence to eliminate any confusion.

- Thanks again for your efforts, if these revisions I mentioned above could be done, I believe the manuscript would contribute to the science. Then, I would like to review the research again.

Final comment: All above mentioned reasons are very fundamental weaknesses of this paper. In my opinion, this paper is not at the level of publishable standards. For the reasons given above, my decision is major revisions for this study.

\section{Reviewer \#5:}

[Reviewer \#5 - Comment 1] Keywords - possibly include 'green infrastructure'?

Response: The term is now added to the keywords, thanks for the suggestion.

[Reviewer \#5 - Comment 2] Abstract - should APT be defined on first use in the abstract as it is used frequently in the abstract and is not defined until page 3 line 3.

Response: APT is now defined in the abstract.

[Reviewer \#5 - Comment 3] Introduction - double space after 'outside is' on 5th line down in 1st para in introduction

Response: Double spaces are all removed.

[Reviewer \#5 - Comment 4] 2. Active perception technique: - a few double spaces throughout this section

Response: Double spaces are all removed.

[Reviewer \#5 - Comment 5] 2.1 Participants - If these were all PhD students were their views from their offices similar or were they based in different locations with differing views?

Response: For clarification following paragraph is added to section 2.1 of the manuscript:

"Participation in the study was not limited to a particular university building or campus. However, $86 \%$ of the participants were based on the University of Auckland city campus, while the rest distributed among six different campuses around the city. Participants were mostly from the faculties of Science (24\%), National Institute of Creative Arts and Industries (NICAI) (22\%), Engineering (16\%) and Bioengineering Institute $(12 \%)$. The low response from postgraduate students in the University of Auckland Business School is due to the school policy that the research advertisement could only be distributed through the School Facebook page. The view of the participants from their offices were diverse depending on the location of the buildings in the campus and their rooms/desks within that buildings."

[Reviewer \#5 - Comment 6] What time of year were the sketches drawn - was this standard for all or did this differ?

Response: Following paragraph has been added to Section 2.2 'Procedure' to address this comment and to add clarification to the manuscript:

"The majority of interviews were conducted between July and August; only $19 \%$ were held between November and December. Initially, it was intended to repeat the study in the opposite season. As the data collection started and progressed in wintertime, it was noticed that trees and greenery were drawn as if they still had leaves and/or flowers present. Absence of seasonal variation might be because sketches were drawn from memories. Based on this observation, it was decided to cancel the follow-up interview sessions."

[Reviewer \#5 - Comment 7] 2.3 Analysis 4th line down in this section change 'data-sheet was' to 'data-sheet were'

Response: The manuscript is corrected accordingly.

[Reviewer \#5 - Comment 8] 3 Results and discussion - on the last line of the first paragraph, can 'associated with' be changed to 'representative of'? 
Response: Thanks for the suggestion, the manuscript is revised accordingly.

Blocking buildings (figure 2) - this term is described later but could do with being defined for this diagram

Response: The term is now described earlier in Section 3 with analysis of Figure 2

[Reviewer \#5 - Comment 9] In the first paragraph on page 7 the term 'positively preferred' is used. I am not sure what this means. Could this term be changed or explained?

Response: This term has been revised and replaced with 'positively rated on the Likert scale'

[Reviewer \#5 - Comment 10] Also, the term 'negatively preferred' is used later in the section; does this mean disliked?

Response: This term is now revised and replaced with 'negatively scored on the Likert scale'

[Reviewer \#5 - Comment 11] The last sentence of page 7 begins with 'Such a result is not surprizing...'. I am not sure what is meant by this sentence. Does it mean that the dislike of roads may be a result of associated noise pollution more than aesthetic appearance?

Response: To provide clarification, following sentence is added to the manuscript:

"...In particular, we believe that a higher need for acoustic privacy in residential places did not let the participants of our study judge the roading based purely on visual contribution ".

3.1 The Effect of Features on Windowscape Preferences

[Reviewer \#5 - Comment 12] On the first line of the first paragraph: can the term 'preference group' be explained?

Response: The term 'preference group' is now changed to 'preference category' which has been explained as below: "...The window views are categorised into four preference categories depending on how the overall view have been rated by the participants. As only four windowscapes were rated as Strongly Disliked; it was decided to merge them into the disliked category."

[Reviewer \#5 - Comment 13] On line 3 of this paragraph: Can the word 'that' be inserted? - 'For all the features' that 'appeared in...'

Response: The manuscript is revised accordingly.

[Reviewer \#5 - Comment 14] In line 6 of this paragraph: Can the words 'number of' be inserted? - This difference is because complexity, the average' number of' features in the view...

Response: The manuscript is revised accordingly.

[Reviewer \#5 - Comment 15] Table 1: I feel that the legend is insufficient and does not explain what is shown by the information. How does the top section with the word clouds relate to the bottom section and what does the bottom section show? Are these two separate tables? I find the word clouds very difficult to compare as the features are not in the same place between the 'like', 'strongly like', 'not sure'... sections. Why are some of the features highlighted in the bottom section?

Response: Table 1 is completely revised; word cloud is removed as it seemed that it caused more confusion than adding value to the manuscript.

General comments

I think that this concept and methodology is very interesting, and I would definitely consider this approach as a useful and informative tool.

[Reviewer \#5 - Comment 16] Some areas of the article require further explanation, particularly what is shown in the figures and tables.

Response: To address this comment, further explanations are added in several parts of this manuscript particularly for Figure 1, Figure 2 and Table 2.

[Reviewer \#5 - Comment 17] It would be beneficial to have some indication of the types of views used. Could you do something similar to how you have explained the break up of the age demographic to show the ratios of park views, those with a moderate amount of greenery, to inner city highly urbanised views etc.

In the results discussion section it states that there is a variety of Auckland windowscapes but I think this needs unpacking.

Response: A paragraph is added to results and discussion section to address this comment.

[Reviewer \#5 - Comment 18] The figure legends are very brief, I feel they are insufficient in explaining what the data represented is saying. These figures cannot be interpreted on their own without reading the document. I especially 
struggled with table 1 . Here is the same data in the wordclouds and in the table? If so, do we need both?

Response: Legends for figures and tables are revised.

\section{Reviewer \#6:}

Please add comments you don't mind the author seeing. General Comments:

[Reviewer \#6 - Comment 1] My comments relate to the page numbers of the pdf I cannot figure out how the wordclouds fit in - and it does not seem to fit the rigor of the study - However I may be wrong perhaps it just needs to be explained more simply

Response: Table 1 is completely revised; word cloud is removed as it seemed that it caused more confusion than adding value to the manuscript.

[Reviewer \#6 - Comment 2] Page 2 Line 44 _ Why is the 1st reference 2 and not 1?

Response: The reference sequences are now corrected in the manuscript.

[Reviewer \#6 - Comment 3] Page 48 - I don't think you can say this: "As a result, vision is the dominant sense that connects urban residents to landscapes." I think that you can say that as we spend so much time indoors that the view that we get outside is important, and it has been proven that views outside improve health and wellbeing?

Response: Both abstract and introduction are revised to address this comment.

[Reviewer \#6 - Comment 4] Line 59 - Urban areas have highly complex structures

Response: This is now corrected in the manuscript

[Reviewer \#6 - Comment 5] Page 3 Line 47 - The results

Response: This is now corrected in the manuscript

[Reviewer \#6 - Comment 6] Page 6 Figure 1 - what is the source?

Response: A paragraph is now added explaining further explain the process of analysing and clarifying how Figure 1 is obtained.

[Reviewer \#6 - Comment 7] Page 7 Line 38 - to the appearance of the sky

Response: This is now corrected in the manuscript.

[Reviewer \#6 - Comment 8] Page 8 Above line 1 - why capital The?

Response: It is now corrected in the manuscript.

[Reviewer \#6 - Comment 9] Page 9 Line 20 - As the research mainly

Response: This is now corrected in the manuscript.

[Reviewer \#6 - Comment 10] Page 11 I thought photos were not used in this study and only views from windows? That is what is implied in the beginning?

Response: A paragraph is added to the 'Procedure' section to clarify the role of photograph in this research.

[Reviewer \#6 - Comment 11] Lines 11-13 - A view through a window I do not think constitutes a 3D experience - it is not immersive and therefore not 3D

Response: It is correct that one cannot immerse in the view from a window; however, what can be viewed from the window is still three-dimensional in the sense that to locate an object within a view three values (parameters are required). Hence the sentence remained unchanged. 